NBSIR 76-1138

\title{
A Proposed Experiment to Evaluate Environmental Dependence of the Measure- ment of Noise from Medium and Heavy Duty Trucks
}

Curtis I. Holmer and Roger D. Kilmer

Applied Acoustics Section Institute for Basic Standards

National Bureau of Standards

Washington, D. C. 20234

September 1976

FINAL REPORT

Prepared for

The Motor Vehicle Manufacturers Association of the United States of America

320 New Center Building

Detroit, Michigan 48202 


A PROPOSED EXPERIMENT TO
EVALUATE ENVIRONMENTAL
DEPENDENCE OF THE MEASURE-
MENT OF NOISE FROM MEDIUM
AND HEAVY DUTY TRUCKS

Curtis I. Holmer and Roger D. Kilmer

Applied Acoustics Section

Institute for Basic Standards

National Bureau of Standards

Washington, D. C. 20234

September 1976

FINAL REPORT

\section{Prepared for}

The Motor Vehicle Manufacturers Association

of the United States of America

320 New Center Building

Detroit, Michigan 48202

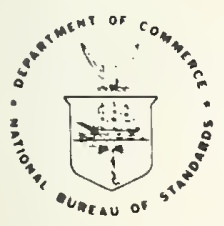

U.S. DEPARTMENT OF COMMERCE, Elliot L. Richardson, Secretary Edward O. Vetter, Under Secretary

Dr. Betsy Ancker-Johnson, Assistant Secretary for Science and Technology

NATIONAL BUREAU OF STANDARDS, Ernest Ambler, Acting Director 

Abstract

1. Introduction

2. Technical Background for Experiments

2.1. Proposed Test Procedures

a. SAE J366b Description

i. Test Site

ii. Vehicle Operation

iii. Instrumentation

iv. Measurement Procedure

b. DOT Interstate Motor Carrier Noise Emission Regulation 6

i. Test Site

ii. Vehicle Operation

iii. Instrumentation

iv. Measurement Procedure

2.2. Propagation of Sound over a Reflecting Plane

2.3. Potential Effects of Environment

a. Effects of Environment on Noise Emission

b. Effects of Environment on Noise Propagation

c. Variables to be Considered

2.4. Stationary Simulation versus Moving Tests

2.5. Near Field Sound Power Level

2.6. Statistical Aspects of the Experiment Design

a. Accuracy and Precision Considerations 22

b. Data Reduction and Data Analysis 22

c. Sensitivity of the Experiment. 23

2.7. Objectives and Goals of a Proposed Experiment 24

3. Proposed Experiment

3.1. Overview of the Experiment

a. Proposed Test Site

i. Moving Tests

ii. Stationary Tests 
b. Proposed Vehicles

c. Data Acquisition and Reduction Systems

3.3. Moving Tests

a. Test Parameters

b. Test Plan for Moving Tests

3.4. Stationary Vehicle Tests

a. Test Parameters

b. Test Plan for Stationary Tests

3.5. Variations from the Proposed Test Plan

a. Change in Scope from Evaluation of Preliminary Data

b. Changes in Experiment because of Vehicle Mounted Near Field Microphones

4. Data Reduction and Reporting

4.1. Data Reduction

4.2. Presentation of Reduced Data

4.3. Reports

5. Data Analysis

6. Appendix A. Description of A Data Reduction Mathematical Model 59

7. References 
A PROPOSED EXPERIMENT TO EVALUATE ENVIRONMENTAL DEPENDENCE

OF THE MEASUREMENT OF NOISE FROM MEDIUM AND HEAVY DUTY TRUCKS

$$
\begin{aligned}
& \text { C. I. Holmer } \\
& \text { R. D. Kilmer- }
\end{aligned}
$$

Increasing concern with the impact of transportation noise on communities has led to an increase in the number of motor vehicle noise regulations at a11 levels of government. As regulations become more widespread, the accuracy and precision of vehicle noise measurements become more critical since each uncertainty in the measurement requires a corresponding increase in the margin that manufacturers must allow between the regulated noise limit and vehicle design levels. Although considerable uniformity has been achieved by existing voluntary standards, there remain significant variations between noise measurements made at different sites or at different times on the same site. These variations are attributable to differences in the environment, including site and meterological influences. Thus, there is a need for systematic investigation of the various environmental and test site effects on noise generation, radiation and/or propagation. This report presents the findings of a feasibility study for an experiment to investigate environmental effects on truck noise emission measurements. The result of this study is a proposed experiment designed to examine the systematic and nonsystematic dependence of observed truck driveby noise on the environmental effects present during the measurement. The experiment is designed in such a manner as to permit separation of emission and propagation effects. Although it may not be feasible to determine "correction factors" for environmental effects within the time and financial constraints of this experiment, it is fully expected that the data obtained from this experiment will reveal the magnitude of variations in the measurement and provide a broad enough information base for study of the underlying physical mechanisms.

Key Words: Acoustics; environmental conditions; noise measurement; noise (sound); transportation noise; truck.

\section{INTRODUCTION}

This report represents the findings of a feasibility study for an experiment to investigate environmental effects on truck noise emission measurements. In the remainder of this introduction and in section 2, a non-technical review of the anticipated effects from the environment is presented. The influence of these factors on experiment design are then presented in sections 3 and 4, in the form of a detailed experiment plan, which, if followed, is expected to provide an adequate data base for subsequent analysis to determine physical mechanisms which produce the observed changes. The general form of these analyses is discussed in section 5. The conclusion of this feasibility study is that the present state-of-the-art of acoustic measurements permits the design of an experiment which may be expected to reveal the magnitude of variations in the measurement and to provide a broad enough data base for study of physical mechanisms, within realistic time and financial constraints. 
The purpose of this experiment is to provide a data base for the evaluation of the effects of weather variables on truck noise measured in accordance with the driveby test procedures of SAE Standard J366b and the stationary test procedures of the Department of Transportation interstate motor carrier noise emission regulations. The principal objectives of the experiment are to: 1) Rank order, in terms of significance of variation induced in measured truck sound level, the principal environmental variables associated with vehicle noise measurement; and 2) Identify to what extent these variations are due to changes in the propagation path, and conversely to what extent they represent changes in the vehicle sound emission.

This experiment is designed to answer two significant questions: 1) Are the data obtained in vehicle noise emission measurements systematically dependent on ambient weather conditions at the time of the test?; and 2) Are the data obtained in stationary vehicle simulations of a driveby test statistically equivalent to moving driveby tests? The importance of these questions lies in the consequences of positive answers.

In the event that the answer to question one is positive (i.e., there are systematic dependences) then the next logical step is to seek physical mechanisms that explain these changes either through explanation of changes in the vehicle emission or of characteristics of the sound propagation from the vehicle to the measurement location. Once the region in which the predominant changes that occur are identified, then physically or empirically based models can be constructed for anticipating effects of environmental variations. These models might then be used to design further studies of measured data on other vehicles, in order to provide corrections for systematic changes; or to produce more adequately documented environmental limtations for vehicle measurements.

The purpose of posing the second question is two-fold, and includes the validation of a stationary test for use in assessing changes in vehicle emission with environmental effects, plus the possibility that such a test procedure may be attractive in its own right for assessing vehicle noise emission.

Even in the event that the questions raised above are answered in the negative, we expect that the developed data base will provide a means for assessing the role of weather variables in determining the imprecision of these measurements. This determination will permit those engaged in measurement of motor vehicle noise emissions to assess the probable uncertainty of measurements. of vehicle noise on a more rational basis than at present, and thus to choose environmental condition limits which are appropriate to the test requirements.

\section{TECHNICAL BACKGROUND FOR EXPERIMENTS}

There are many variables which potentially could alter the sound level measured during a truck driveby. In the following sections we provide brief 
discussions of those aspects which influence the design of this experiment, both in terms of factors to be studied, and those for which controls are to be designed. These discussions should be viewed in terms of the net impact of the particular item on the overall approach to the problem. These impacts will then be summarized in terms of the specific goals of the experiment.

\subsection{Proposed Test Procedures}

The two procedures which will be utilized in this experiment are SAE $\mathrm{J} 366 \mathrm{~b}$ for driveby and simulated driveby tests and the Department of Transportation (DOT) interstate motor carrier noise emission regulation for stationary run-up tests. The general provisions of these two procedures are discussed in this section.

\section{a. SAE J 366b Description}

The test method predominantly used to measure the exterior noise produced by medium and heavy trucks is the Society of Automotive Engineers (SAE) Standard J366b -- Exterior Sound Level for Heavy Trucks and Buses[1]. If This standard is designed to determine the maximum noise that can be produced by the propulsion system without considering the influence of tire noise. Because of the characteristics of the noise generating mechanisms of trucks, i.e., propulsion system noise increases with engine speed while tire noise increases with vehicle speed (see Figure 1), the tests are conducted at high engine speed and fairly low vehicle speed. The noise level produced during such a test probably represents the worst-case noise level for a truck operating under urban driving conditions. Such a test would, in addition, represent the worst-case propulsion system noise contribution to the overall noise level produced by the vehicle at high speeds.

This standard specifies the test site topography, vehicle operation and instrumentation required to determine the maximum (A-weighted) exterior sound level generated by trucks and buses. These general specifications are discussed in subsections i through iv.

\section{Test Site}

The test site layout shown in Figure 2 consists of the vehicle path including the acceleration point, microphone point, end zone and end point; the triangular shaped measurement area formed by the acceleration point, end point and microphone; and the surrounding terrain within 100 feet $(30.5 \mathrm{~m})$ of either the microphone or vehicle path. The specification for the test site is that it be a level open space free of large reflecting surfaces within 100 feet (30.5 meters) of the microphone or vehicle path. The vehicle path is to be relatively smooth, dry concrete or asphalt free of any extraneous materials. Similarly, the surface of the ground within the measurement area is to be free from powdery snow, long grass, loose soil and ashes.

\section{ii. Vehicle Operation}

The test procedure calls for vehicle operation using both a full throttle acceleration and a closed throttle deceleration. For the acceleration test,

$1 /$ Figures in brackets refer to references at the end of this report. 
VEHICLE SPEED, $\mathrm{km} / \mathrm{hr}$

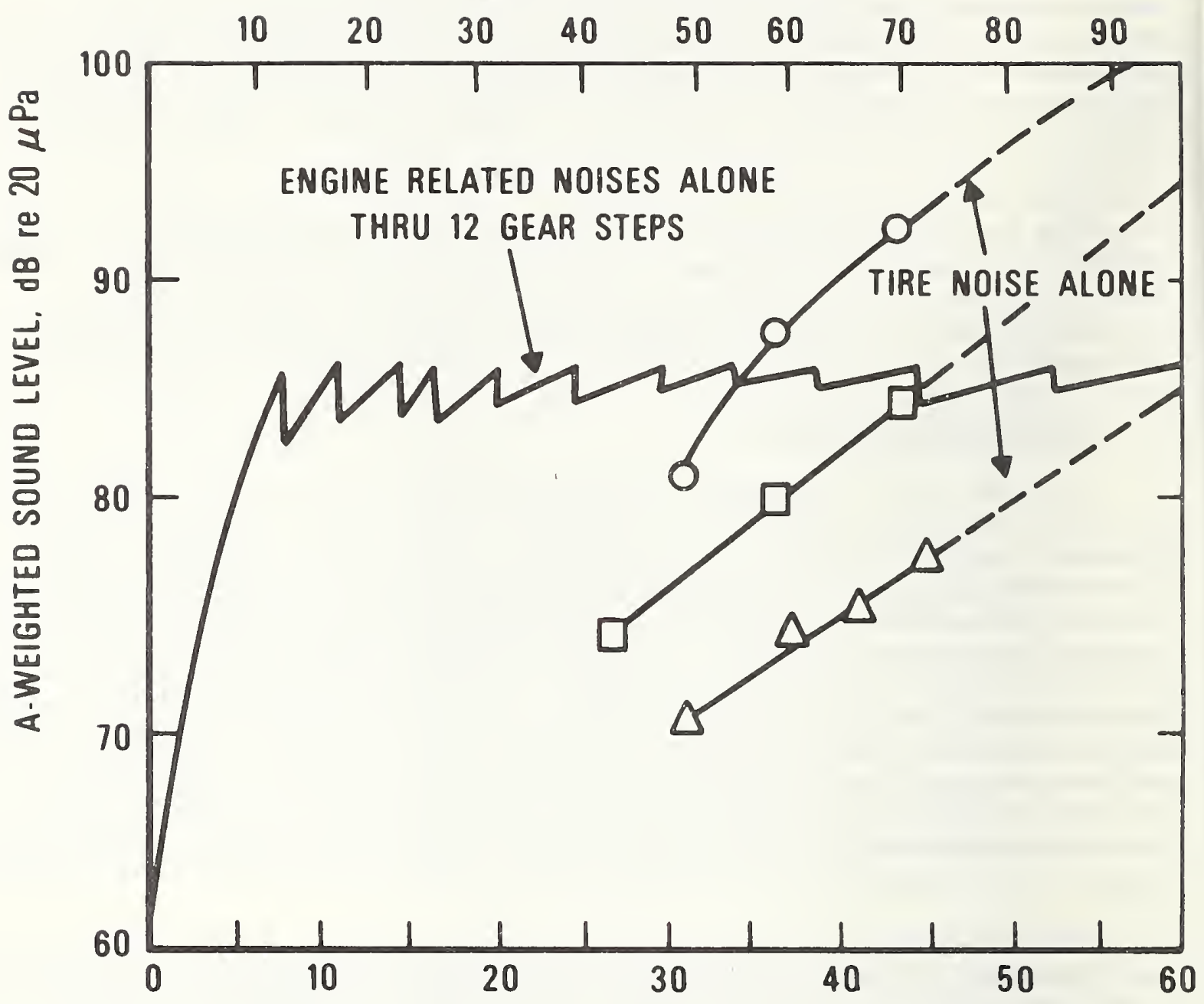

VEHICLE SPEED, mph

TIRE NOISE

\begin{tabular}{|c|c|c|c|}
\hline & STEERING AXLE & DRIVE AXLE & TRAILER AXLE \\
\hline 0 & NEW RIBS & $\begin{array}{c}1 / 2 \text { WORN } \\
\text { X-BARS }\end{array}$ & NEW POCKET RETREAD \\
\hline$\square$ & NEW RIBS & $\begin{array}{c}\text { NEW } \\
\text { X-BARS }\end{array}$ & NEW RIB RETREAD \\
\hline$\Delta$ & NEW RIBS & NEW RIBS & NEW RIB RETREAD \\
\hline
\end{tabular}

Figure 1. Engine related and tire noise for an 18-wheel tractor-trailer as measured 50 feet $(15.2 \mathrm{~m})$ from the centerline of the lane of travel of the vehicle [2]. 


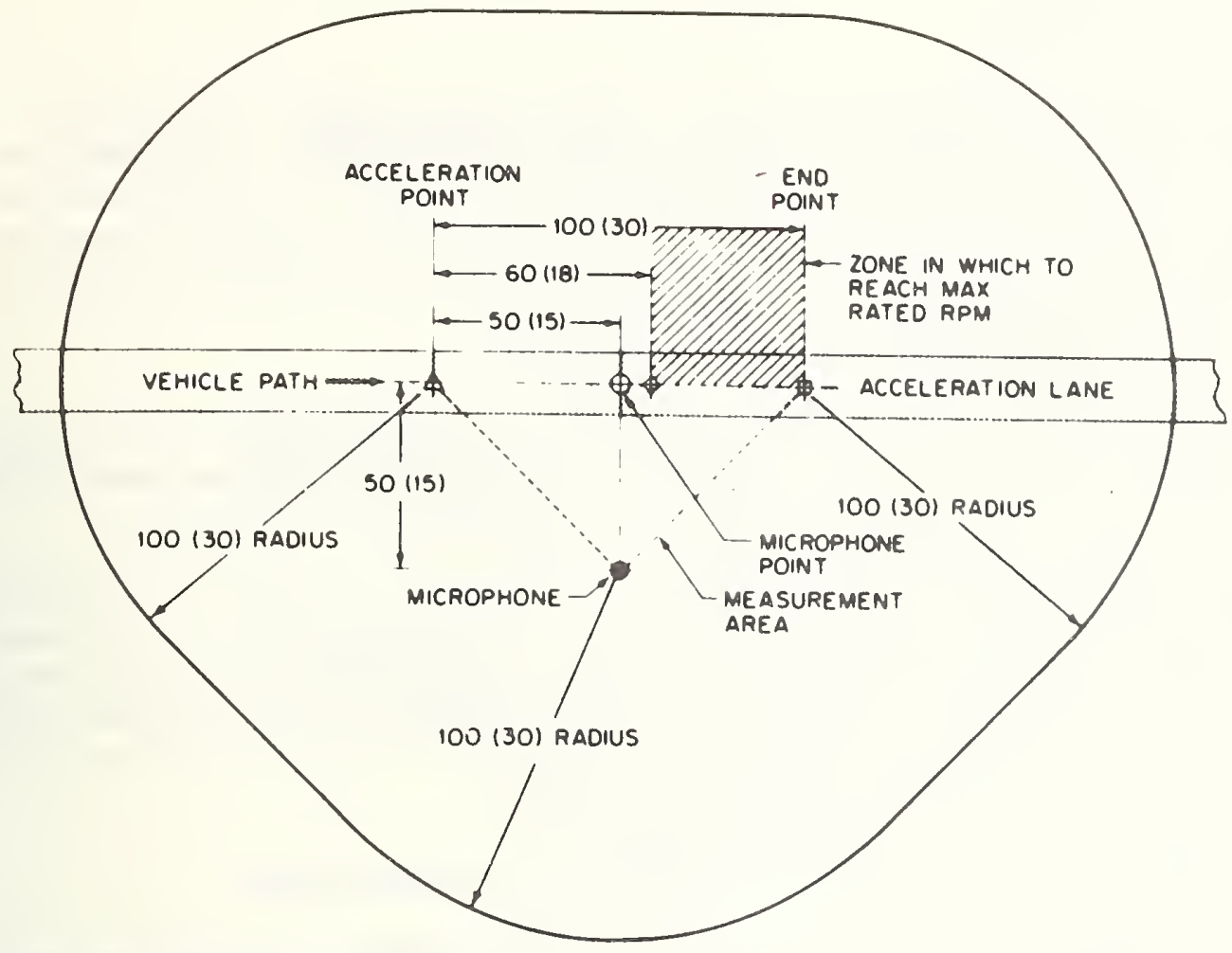

NOTE DIMENSIONS ARE FT $(\mathrm{m})$

Figure 2. Test site specifications given by SAE J366b [1].

the highest rear axle and/or transmission gear and initial vehicle speed are chosen such that at wide-open throttle the vehicle will accelerate from the acceleration point starting at no more than two-thirds of maximum rated or governed engine speed and will reach the maximum rated or governed engine speed within the end zone without exceeding $35 \mathrm{mph}(56.3 \mathrm{~km} / \mathrm{hr})$ before reaching the end point. For the deceleration test, the vehicle is operated at maximum rated or governed engine speed in the gear selected for the acceleration test until reaching the microphone point where the throttle is closed and the vehicle allowed to decelerate to one-half of maximum rated or governed engine speed. If the vehicle is equipped with an exhaust brake, the deceleration test is to be repeated with the brake full on immediately following closing of the throttle. [In the majority of cases the maximum noise is generated during the acceleration mode of operation provided that the vehicle is not equipped with an engine brake[2]. This will be checked during the first week of the first field trip and, assuming this holds true for the three vehicles being tested, only driveby acceleration tests will be performed during subsequent field trips as discussed in section 3.] 
The instrumentation to be used consists of a sound level meter which meets the Type 1 requirements of ANSI S1.4-1971[3]. As an alternative to directly reading the sound level meter, a microphone or sound level meter may be used with a magnetic tape recorder and/or graphic level recorder or indicating meter, providing the system meets the requirements of SAE J184[4].

\section{iv. Measurement Procedure}

The measurement procedure consists of determining the highest sound level with the meter set for "fast" response using the A-weighting network for the acceleration and deceleration of the vehicle as described above.

These measurements are to be made only when the ambient or background noise is at least $10 \mathrm{~dB}$ lower than the level of the tested vehicle and the wind velocity is below $12 \mathrm{mph}(19.3 \mathrm{~km} / \mathrm{hr})$. The sound level for each side of the vehicle is to be the average of the two highest readings which are within $2 \mathrm{~dB}$ of each other and the value to be reported is the sound level for the side of the vehicle with the highest readings.

b. DOT Interstate Motor Carrier Noise Emission Regulation

To establish procedures for determining whether commercial motor vehicles conform to the Interstate Motor Carrier Noise Emission Standards of the Environmental Protection Agency[5], the DOT Bureau of Motor Carrier Safety issued CFR 325 -- Compliance with Interstate Motor Carrier Noise Emission Standards[6]. This regulation specifies the test site topography, instrumentation and vehicle operation for determining the maximum A-weighted sound level generated by motor vehicles with a gross combination weight rating of 10,000 pounds $(4536.0 \mathrm{~kg})$ or more during driveby and stationary run-up operations.

For the purposes of this proposed experiment all driveby tests will be performed according to $\mathrm{SAE} J 366 \mathrm{~b}$ procedures and only the stationary run-up tests of CFR325 will be investigated to study the influence of environmental factors on the measured sound levels. The remainder of this section provides a discussion of the general specifications of this regulation for stationary tests. Although variances in the specifications are given, in our proposed experiment only the standard recommended test site and instrumentation specifications will be utilized.

\section{i. Test Site}

The test site layout shown in Figure 3 consists of the microphone target point, microphone location point, measurement area and the surrounding terrain within 50 feet $(15.2 \mathrm{~m})$ of either the microphone target point or location point. The microphone target point is established on the ground surface of the site on the centerline of the lane in which the vehicle is parked at a point within 3 feet $(0.9 \mathrm{~m})$ of the vehicle's exhaust outlet $(\mathrm{s})$. The microphone location point is established not less than 35 feet $(10.7 \mathrm{~m})$ and not more than 83 feet $(25.3 \mathrm{~m})$ [50 feet $(15.2 \mathrm{~m})$ is the recommended distance] from the microphone target point. The measurement area is the triangular area 


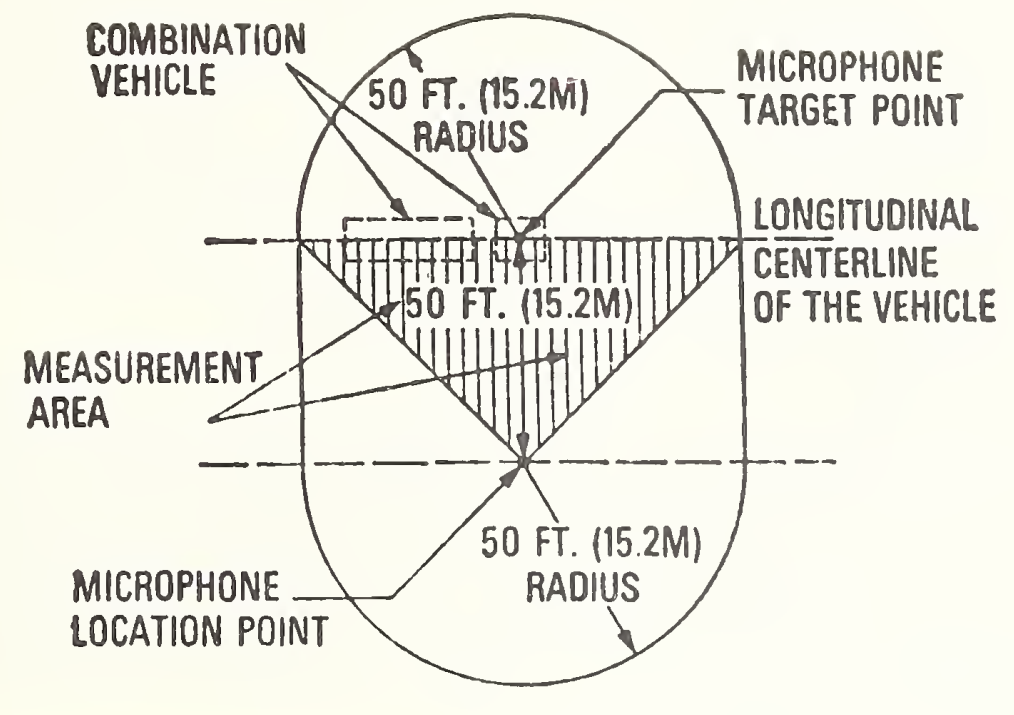

\section{STANDARD TEST SITE: STATIONARY TEST}

Figure 3. lest site specifications given by DoT interstate motor carrier noise emission regulation [6].

formed by the microphone location point and two points 50 feet ( $15.2 \mathrm{~m}$ ) along the centerline of the vehicle on either side of the microphone target point (see Figure 3).

The test site specifications are similar to those of SAE J366b, but are in general less stringent. It is recommended that the measurement area be a "hard" site (i.e., a ground surface covered with concrete, asphalt, packed dirt, gravel or similar reflective material), but a "soft" site (i.e., a ground surface covered with grass or sinilar abșorptive material) can also be used if appropriate correction factors are applied to the measured sound levels. The test site should be a level open space free of large reflecting surfaces with 50 feet $(15.2 \mathrm{~m})$ of the microphone target point or location point. However, certain objects specified by the regulation may be within the test site boundaries and still permit testing.

\section{ii. Vehicle Operation}

For stationary measurements, the vehicle is parked on the test site and 
all auxiliary equipment designed to operate at vehicle speeds of $5 \mathrm{mph}(8.0$ $\mathrm{km} / \mathrm{hr}$ ) or less are turned off. If the vehicle is equipped with a device which automatically disengages the fan, the vehicle should be parked with the engine running for a sufficient length of time (but not more than 10 minutes) to permit the fan to disengage when the vehicle's noise emissions are measured. With the transmission placed in neutral and the clutch engaged, the engine is rapidly accelerated from idle to the maximum governed speed with wide open throttle. After the maximum governed speed is reached the engine is returned to idle.

\section{iii. Instrumentation}

The instrumentation to be used consists of a sound level meter which meets the requirements of ANSI S1.4-1971[3] for a Type 1 or Type 2 sound leve1 meter. A Type $\mathrm{S}$ sound level meter is also permitted provided it has A-weighting frequency response, fast dynamic characteristics of its indicating instrument and a relative response level tolerance consistent with S1.4 specifications for either Type 1 or Type 2 sound level meters.

iv. Measurement Procedure

The measurement procedure consists of determining the maximum reading of the sound level meter for rapid engine accelerations as described above. These measurements are to be made only when the ambient or background noise is at least $10 \mathrm{~dB}$ lower than the level of the tested vehicle and the wind velocity is less than $12 \mathrm{mph}(19.3 \mathrm{~km} / \mathrm{hr})$. The reported sound level is the numerical average of the two highest readings which are within $2 \mathrm{~dB}$ of each other.

\subsection{Propagation of Sound over a Reflecting Plane}

The presence of a reflecting plane influences the sound field around a source through two mechanisms, including reaction back on the source by reflections from the surface, and the interference between direct and reflected signals as they propagate away from the source[7,8,9,10]. Since the effects of reflection usually are small (e.g., less than $1 \mathrm{~dB}$ ) for sources more than 0.75 wavelengths from the reflecting surface, and the principal truck sources which contribute to A-weighted noise are situated further than this from the ground plane, we will only consider the propagation effects at this time. Figure 4 schematically shows propagation paths from a source to a receiver. For source and receiver elevated above the ground plane, two propagation paths (for the direct and reflected signals) occur. The path length difference for these two paths depends on the height of the source and receiver above the ground plane and the separation between them. The phase difference along the two paths is the factor which is responsible for the acoustic effects. This phase difference in radians is defined as the path length difference in wavelengths of sound times $2 \pi$. When the path length difference is an integral multiple of a wavelength, the phase difference of the two signals is such that they add constructively. Since the wavelength is determined from the speed of sound divided by frequency, the phase difference for a particular geometry is frequency dependent. Figure 5 shows a plot of 


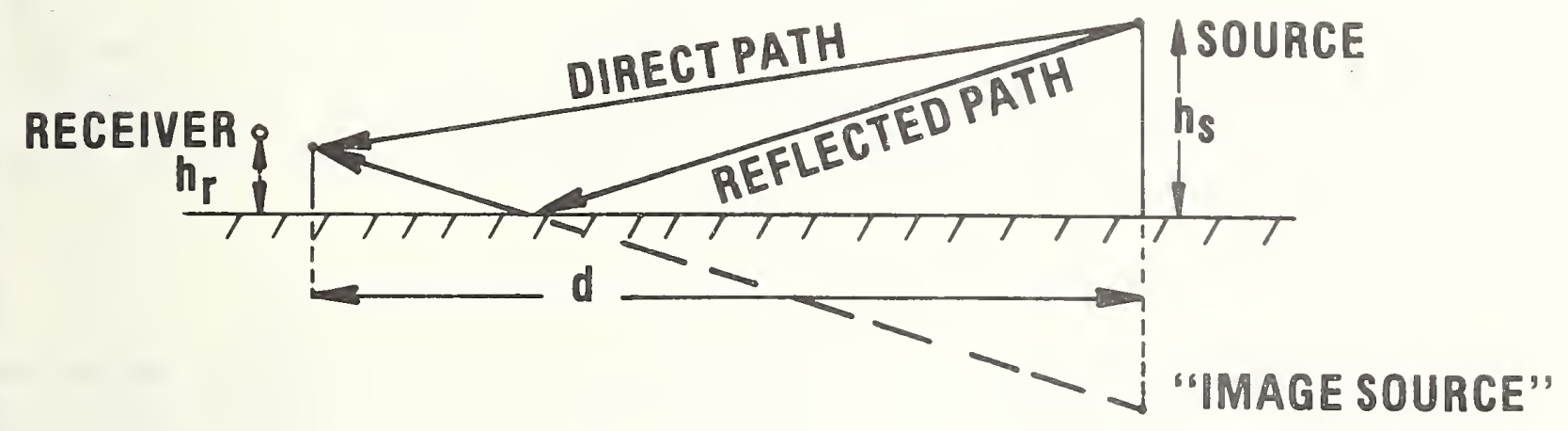

Figure 4. Geometry for sound propagation over a reflecting plane.

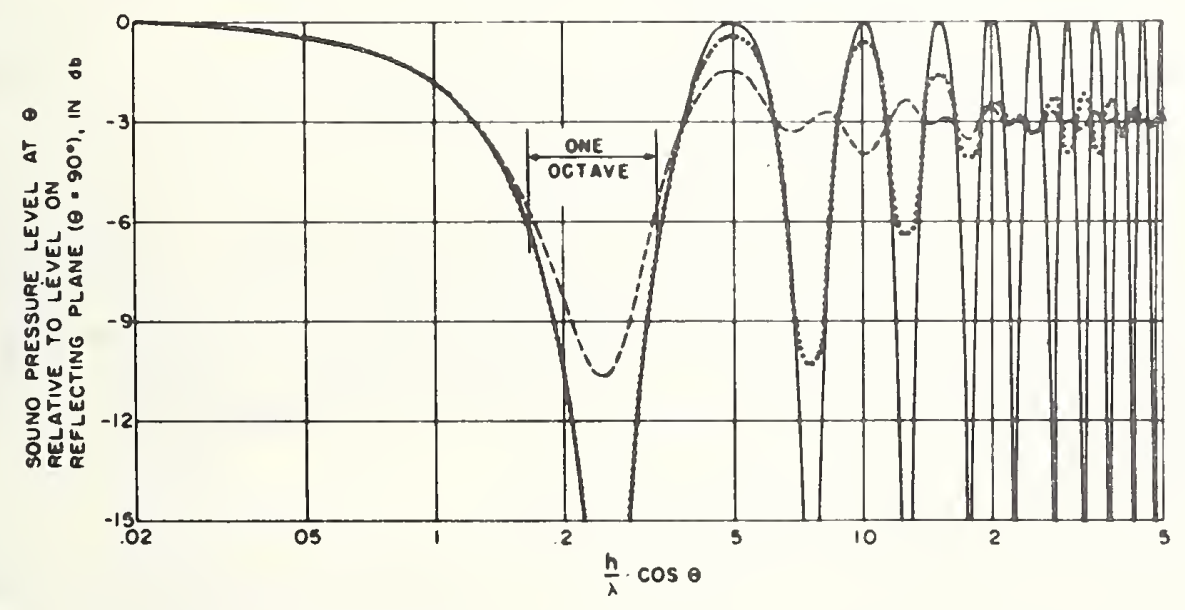

- pure tone

$\begin{array}{l}\text { l/3 octave } \\ \cdots \cdots \\ \cdots\end{array}$ full octave $\}$ effective band width

Figure 5. Directivity of sound field of a point source above a perfectly reflecting infinite plane (after Baade [9]). 
the dimensionless frequency dependence of the interference pattern, while Figures $6 \mathrm{a}, \mathrm{b}$ and $\mathrm{c}$ give the apparent change in the frequency dependence of the "transmission function" for an omnidirectional source of height 4 meters for three different source positions simulating the first position of a driveby test (the second portion of the driveby test, i.e., from the microphone point to the end point, is just the reverse order of these three figures). As can be seen from these data, the effect of the presence of the ground plane is the introduction of considerable frequency dependence. Further, since the interference pattern depends on the geometry and the local effective speed of sound, it may be expected that the full implications of these effects cannot be fully understood from tractable analytic models of simplified source configurations, but rather will require a substantial experimental data base in order to evaluate the relative significance of the many variables.

\subsection{Potential Effects of Environment}

Both steady and fluctuating changes in environment can induce variations in the noise levels measured for truck drivebys. In investigating the effects of changes in environmental parameters, the problem can be divided into three parts:

o Generation of the noise by the propulsion system and associated auxiliary equipment,

- Radiation from the various vehicle noise sources into the surrounding atmosphere, and

- Propagation of the noise from the immediate vicinity of the vehicle to the measurement point.

Each of these processes may be affected independently by changes in the environment; thus an investigation which treats generation, radiation and propagation individually must be performed in order to separate these dependences. A brief discussion of noise emission, 1.e., generation and radiation, is presented in section $a$. The succeeding section will deal with the problem of the effects of environment on noise propagation.

\section{a. Effects of Environment on Noise Emission}

The effects of changes of environment on noise generation can be qualitatively described by considering the individual truck noise sources, i.e., engine structure vibration, exhaust outlet, air intake and fan. For example, changes in the inlet air (i.e., temperature, humidity and/or barometric pressure) result in changes of the combustion pressure which in turn causes changes in the engine structure vibration. These environmental changes would also affect the sound radiated because of changes to the radiation resistance provided by the atmosphere, in particular changes in the characteristic acoustic impedance of the atmosphere, $\rho c$. 


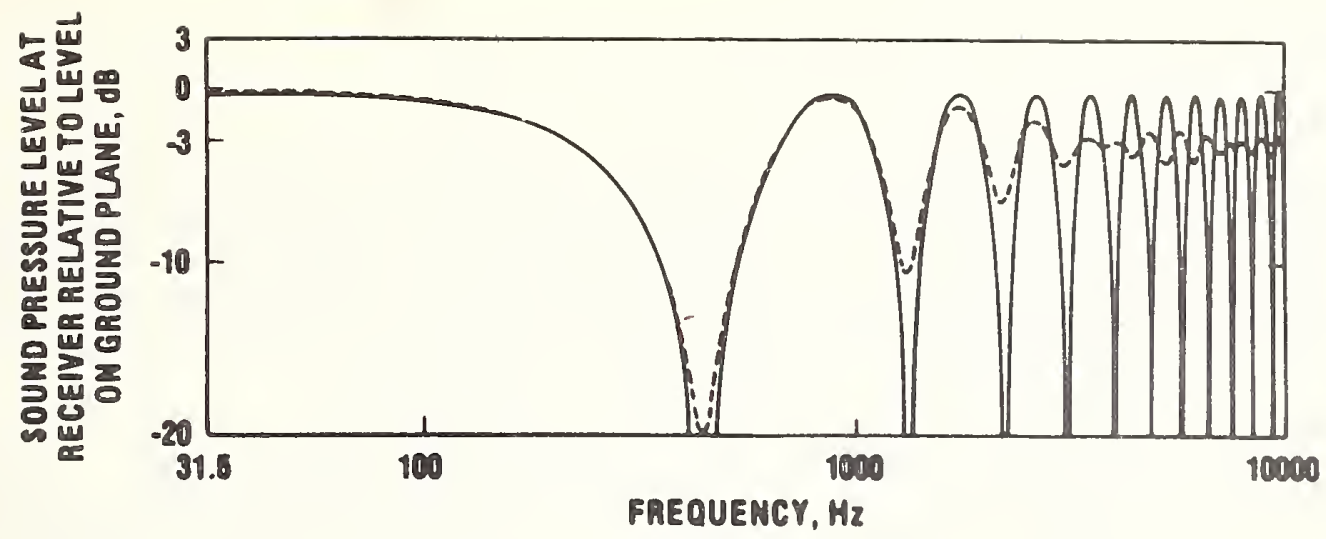

a) Source $4 \mathrm{~m} \mathrm{high}$, receiver $1.2 \mathrm{~m}$ ( 4 feet) high, separation $24.4 \mathrm{~m}$ (start of establish full throttle zone)

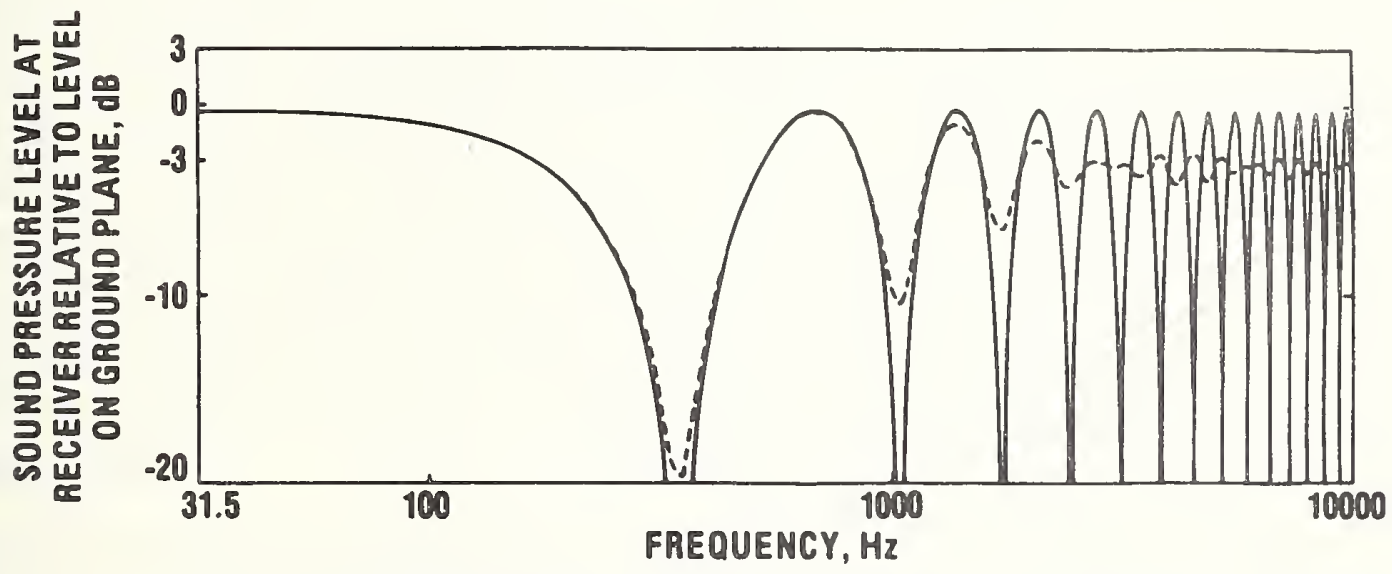

b) as above but separation $19.0 \mathrm{~m}$ (end of establish full throttle zone)

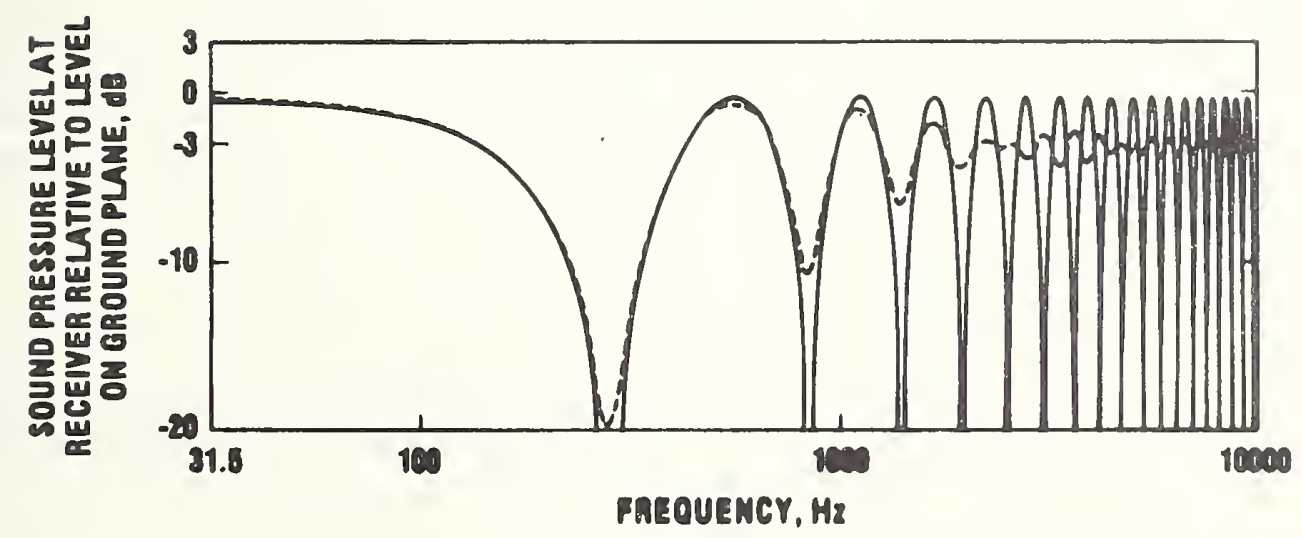

c) as above but separation $15.2 \mathrm{~m}$ (50 foot microphone point)

Figure 6. Transmission function for sound propagation from an omnidirectional source of height $4 \mathrm{~m}$ to the SAE J366b microphone position for three points simulating a driveby test. The solid curves correspond to a pure tone source and the dashed curves to a $1 / 3$ octave band random noise source. 
For the exhaust and inlet noise, radiation cannot be easily decoupled from generation. In general, exhaust and inlet nolse are related to mass flow through the engine and to the ambient acoustic impedance. Changes in the environment which would change the engine performance and therefore, the mass flow and the acoustic impedance, would result in variations in the noise emission from the exhaust and inlet sources.

For fan noise, changes in the environment which result in a change of engine performance, (i.e., a change of engine speed and thus fan speed) would result in a change in noise emission. In addition such influences as steady wind might also affect fan noise emission through a change in effective loading on the fan.

In general, noise generation is a function of engine performance and therefore some measure of engine performance is always required to characterize the circumstances under which noise emission was described. The engine structure vibration is related to combustion pressure which is directly related to engine power. Therefore the noise assoclated with the engine vibration should also be related to engine power. Similarly, since power is related to mass flow, exhaust and inlet noise should also be related to power, although the functional relationship may not be simple. Although fan noise is not directly related to engine power, it is a function of vehicle performance in terms of engine speed. Thus, it appears that the changes in noise emissions may be related to the changes in engine and vehicle performance in terms of power and engine speed.

Other measures such as the inlet air temperature and pressure, engine compartment temperature, and ambient temperature and barometric pressure can be used to estimate the changes of acoustic impedance for the various sources.

\section{b. Effects of Environment qn Noise Propagation}

The determinants of the propagation problem (see section 2.2) are geometry and local effective sound speed. The previously discussed effects of the environment on vehicle noise emission produce their affects through altering the vehicle performance. This change in vehicle performance can also result in an alteration of the "geometry" of the test, in the speclalized sense that with altered vehicle performance (e.g. higher available horsepower), the vehicle may have different operating conditions (e.g., higher engine and fan speed) at each position along the test site. This could result in changes in the position from which "maximum sound" is radiated, so that the propagation paths may be different. The principal sources of measurement variation are expected to arise from changes in the local effective sound speed. These changes can arise from steady effects which change the speed of sound uniformly everywhere, such as changes in mean temperature, mean pressure, and steady uniform wind components in the direction of propagation. In addition, and perhaps more significant for short distance propagation from directional sources, are changes in the propagation path caused by gradients of temperature and wind. These gradients have the effect of curving the ray paths. Figure 7 provides a schematic illustration of the direction of these 


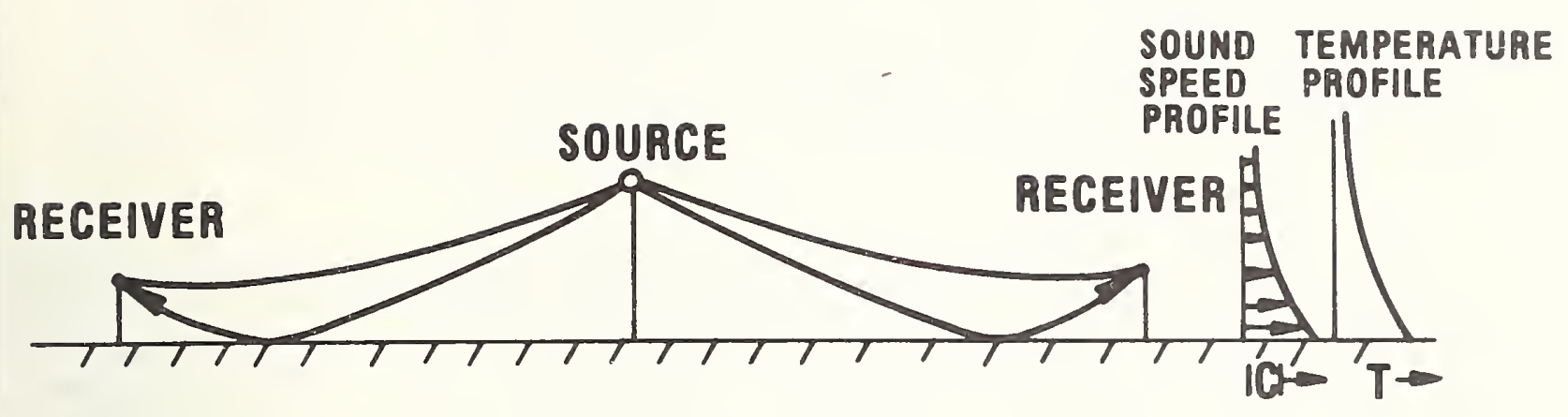

a) Temperature gradient

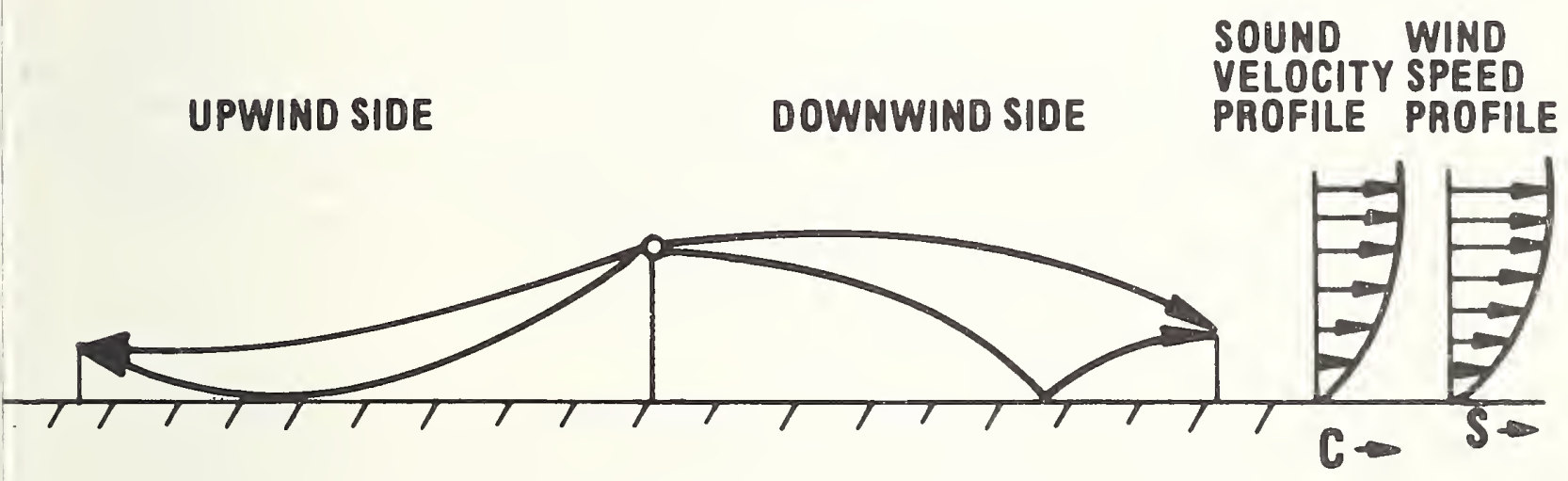

b) Wind gradient

Figure 7. Schematic illustration of changes in propagation paths due to temperature and wind gradients. 
changes. For a number of conditions, the temperature and wind gradients may be of comparable magnitude, with the result that their effects may roughly cancel on the downwind side and add on the upwind side. Of importance on the upwind side is the fact that the curved propagation path implies selection of radiation from a different angular position from the source, which may be highly significant for directional sources such as exhaust pipes at high frequencies.

Still a third form of change in the propagation path is possible due to local fluctuations in phase along the propagation path resulting from wind or thermally induced turbulence. These effects may be viewed as producing fluctuations in the observed levels from a steady fixed source. Figure 8 shows some data[11] for a pure tone source. As can be seen from these figures, the effect of turbulence is to reduce the depth of the transmission path "attenuation" minima as shown in the upper portion of Figure 8. From the middle and lower portions, it is suggested that the maximum level fluctuations occur near the minima in the transmission function, and for propagation on the order of 50 to 100 feet $(15.2$ to $30.5 \mathrm{~m})$, fluctuation levels of $8-12 \mathrm{~dB}$ have been observed for pure tones.

To summarize this discussion, it is seen that steady changes in the environment can lead to steady changes in the "transmission path filter" (e.g., changes in the frequencies of minimum transmission to a particular microphone location) which may lead to spectrum shape dependent changes in the measured level. Further, short term fluctuations in the environment can lead to large scale fluctuations in measured level. Thus, the proposed experiment should provide estimates on the magnitude of temperature and wind gradients over the propagation path, as well as some measure of environmental fluctuations during the acoustic tests.

\section{c. Variables to be Considered}

In view of the above discussions, a broad experiment is required to evaluate the relative significance of the various possible changes. In particular, it is suggested, as a minimum, that the experiment include monitoring the change in the propagation environment and the changes in the vehicle environment (if different), as it relates to vehicle performance. Thus, the minimum set of relevant parameters judged to be necessary to this experiment include:

\section{A. Vehicle parameters}

a) Measures of vehicle performance such as engine speed and horsepower vs. vehicle position.

b) Measures of vehicle environment such as, inlet air temperature and pressure, fuel composition and engine compartment air temperature. 


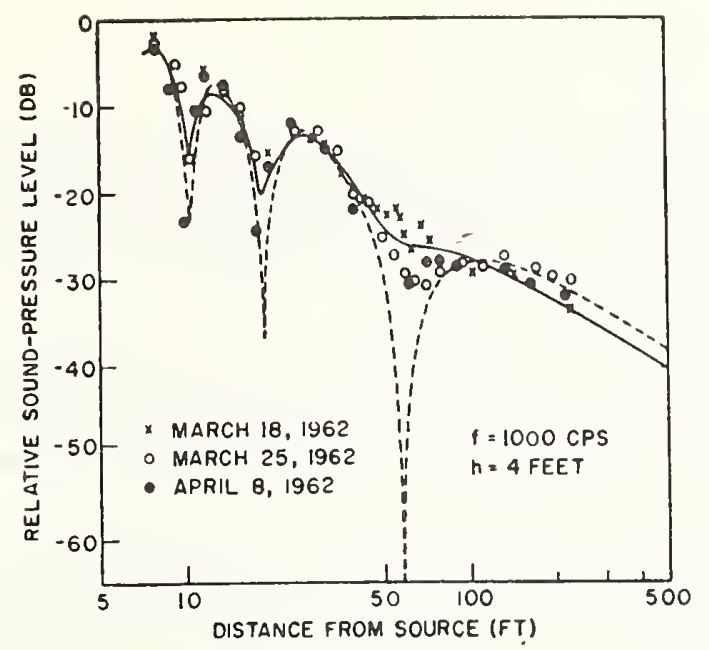

Exprimenta data and the calculated rms sound-pressure level for a small source over a plane boundary $(f=1000 \mathrm{cps})$.

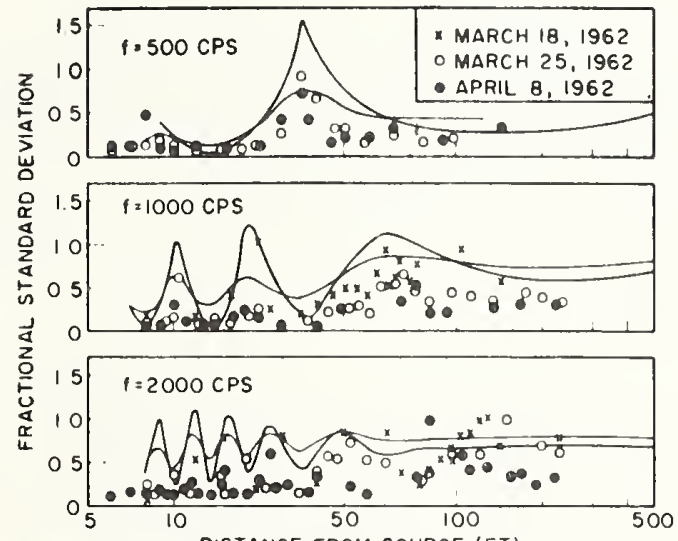

Measured and calculated frac [iom,t] standlurd devi.stion of $\bar{p}^{2}$ as a function of distance.

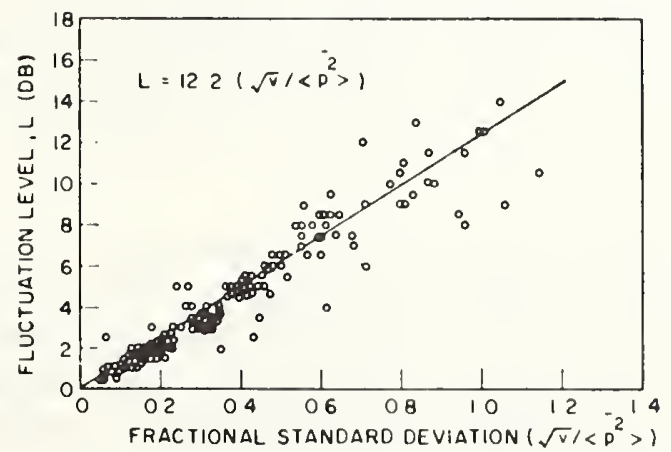

Depentence of the fluctuation lovel (l.) on the fractional standard deviation of the fluctuations.

Figure 8. Effect of turbulence along propagation path (after Ingard and Maling [11]). 
a) Steady environment measures including: mean air temperature and temperature gradient, mean wind speed, direction and gradient, pad surface temperature, relative humidity and ambient pressure.

b) Measures of environmental fluctuation such as: short term, temporal variations in wind speed and direction, and air temperature, as well as estimates of spatial variation over the test pad surface.

These vehicle and environmental measurements must be made concurrent with the acoustic measurements. We have indicated that the propagation path will be perturbed by local fluctuations which will lead to variations in the measured level. These instantaneous fluctuations can be expected to be different at different times and positions on the test surface. Because of the scope of the measurement problem entailed in correlating instantaneous measured sound level with instantaneous fluctuations in the local environment, it is proposed that the scope of this experiment be limited to dealing with the change in average measured levels associated with the change in short time average environment. (average over the time period of one or several driveby or stationary measurements). It is presumed that a measure of the fluctuation in measured sound level (e.g. the standard deviation of the maximum sound level) can be correlated with measures of the magnitude of environment fluctuations.

A last factor of the environment which has to this point gone unmentioned is that of test site variation including test pad size, flatness, composition, and changes of the latter two with time. Evaluation of this effect is hampered by: a) the lack of a defined measurement procedure for any of the above possible forms of variation, b) the confusion caused by the large number of other environmental variables already included in this study, and $c$ ) the relatively small number of test sites available for evaluation in controlled experiments. This study will include some experiments directed at assessing long term (e.g., between measurement trips) changes in the test pad through study of changes in detailed transmission path measurements under "steady" environment conditions. These studies will also hopefully provide background information for future test pad evaluation measurements.

\subsection{Stationary Simulation versus Moving Tests}

The primary reason for including stationary simulation vehicle tests in this study is to provide a basis for separating the effects of environment on vehicle noise emission from the effects on propagation. This separation is obtained by using a near field microphone array to determine the vehicle noise emission without the effects of propagation, which may then be compared to the results determined using a far field microphone array. 
Some questions have been rasied by a recent publication[12] which reports that the variations in noise level of light motor vehicles from day to day and site to site may be primarily due to diffraction in the wake of the moving vehicles. In that study measurements were made at 50 feet ( 15.2 m) for three types of vehicles operating on three different pavements (denoted PA, GA and Conc) using three different procedures:

1) Ful1 throttle acceleration (similar to SAE J986a [13]);

2) Coasting vehicle equipped with an electronic point source (mounted near the rear bumper to simulate the exhaust outlet) emitting five continuous pure tones distributed through the significant part of the exhaust noise spectrum; and

3) Stationary vehicle equipped with the electronic point source.

In addition to these acoustic measurements, the vertical profiles of ambient wind and temperature were also monitored from the ground to a height of either 4 or 5 feet $(1.2$ or $1.5 \mathrm{~m})$. The results of these measurements showed that the sound level deviations for the three vehicles were similar and therefore the deviations were averaged for the three vehicles. The data measured for a full throttle acceleration are shown as functions of temperature at 3 feet $(0.9 \mathrm{~m})$ in Figure 9. In this plot the dotted lines correspond to the data for the three pavements and the solid line to the best least square fit to all the data points. The slope of these curves indicates that the sound level measured at 50 feet $(15.2 \mathrm{~m})$ for the moving vehicle decreases by $1 \mathrm{~dB}$ for a temperature rise of about 14 to $20^{\circ} \mathrm{F}$ ( 7.8 to 11.1 ${ }^{\circ} \mathrm{C}$ ). The results for the electronic source on the coasting vehicle are similar though the data show more scatter. The data for the stationary electronic source plotted in a similar fashion are presented in Figure 10. These results show the measured sound levels increase with temperature. A difference in behavior between stationary and moving sources is thus strongly suggested.

These results may not apply to trucks since the noise source characteristics and locations are different from automobiles. Since there is a possibility of opposite trends for stationary and moving tests, a practical solution is to measure the noise and environmental conditions for both cases and from these results determine the suitability of stationary simulation of driveby tests.

\subsection{Near Field Sound Power Level}

One method of minimizing the effects of propagation when measuring the noise generated by a source located in an outdoor environment is to use a microphone array located close to the source to determine the near field sound power level. The question then arises of how to determine the far field sound power level from the near field measurements and given this, how do the far field results relate to data which would be measured using the SAE J366b procedure. 


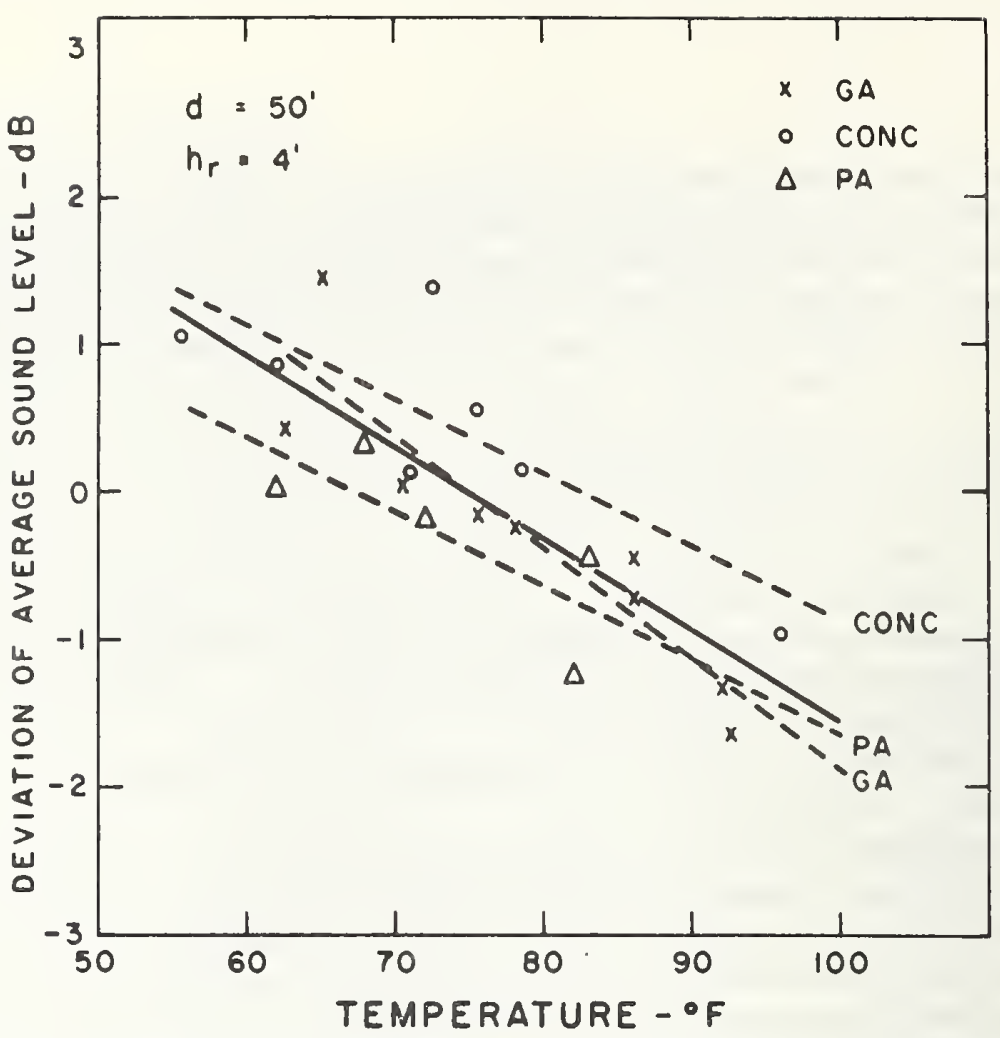

Figure 9. Influence of ambient temperature on measured sound level for automobile drivebys (after Olson, Piercy and Embleton [12]).

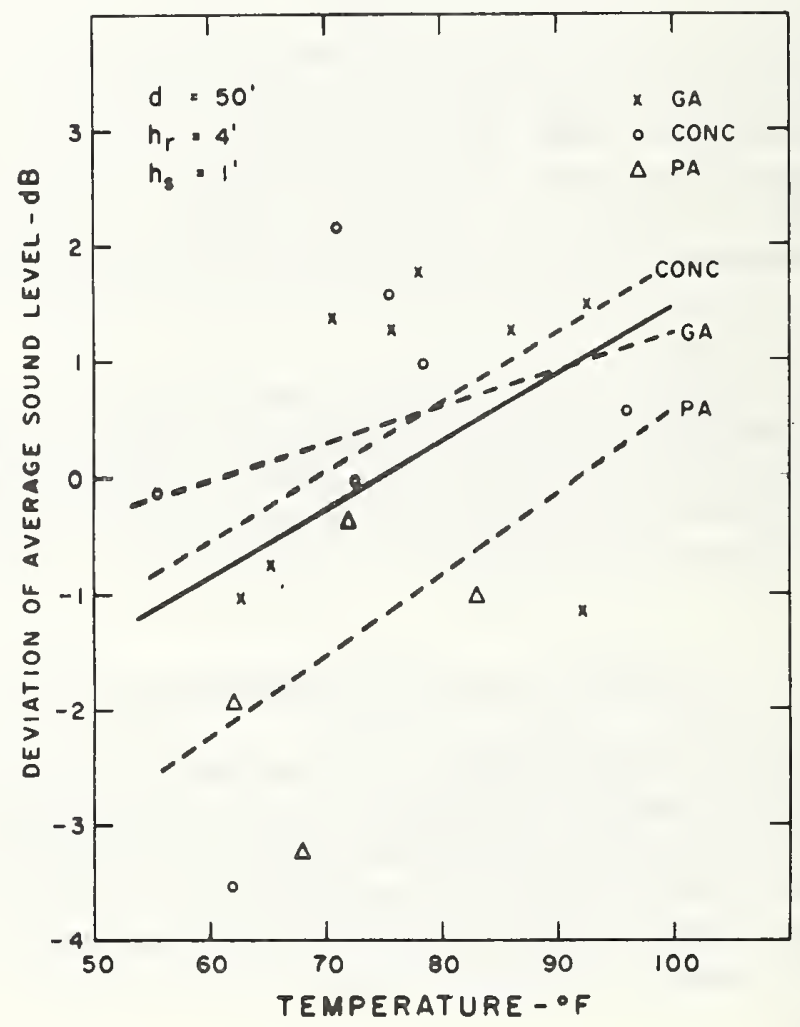

Figure 10. Influence of ambient temperature on measured sourd level for simulated exhaust noise source (electronic point source) mounted on a stationary vehicle (after 0lson, Piercy and Ĺmbleton [10]). 
Reference [14] presents the results of an extensive investigation of the accuracy and precision of various measurement methodologies for determining the estimated sound power output of 17 different portable air compressors, and in particular, a comparison of the results of near field and far field sound power measurements. The near field data consisted of measurements every square meter on a rectangular surface one meter from the machine surface and the far field consisted of measurements on an 84 point hemispherical array of seven meter radius around the source. The sound power was estimated for each case from the product of the impedance of air, times average mean square pressure over the measurement surface times the area of the measurement surface. The deviation of the sound power level estimates based on the near field measurements using a conformal measurement surface from the estimates using the far field measurements are plotted in Figure 11. As shown by these data the deviations are small, with an average deviation of $+0.5 \mathrm{~dB}$ and a standard deviation of the average deviation of $\pm 0.5 \mathrm{~dB}$ for the A-weighted sound power level. The significance of the number of measurement points is shown in Figure 12. These data indicate that an increase in the number of measurement points does not significantly affect the accuracy of the measurement over that for five measurement positions (for that particular sample of data), although, there is a systematic dependence of precision of the comparison for estimation of A-weighted sound power level. Based on this information, the far field sound power level can be adequately estimated with sufficient accuracy by a limited number of near field measurements (on the order of eight).

The sound pressure level as measured using the SAE J366b procedure is then related to the far field sound power level (or alternatively an average rms sound pressure over some particular surface times a directivity function for that particular source) and an interference function dependent on the source/test site geometry. If it is assumed that the directivity and interference functions change in predictable ways, the sound pressure level measured by the SAE J366b microphone can be directly related to the far field sound power level through this analytic model. Assuming the validity of this model, independent of its actual existance, the effects of source variation can then be studied independently of the changes in far field sound level through direct evaluations of variations in the near field sound power level. Recent work in underwater [15,16] and ultrasonic transducer[17, 18, 19] calibration have further indicated that directivity, and therefore changes in directivity, can be estimated from near field measurements through combination of near field measurements with appropriate attenuation and phase shift.

This discussion may be summarized by noting that the postulation of separation of environmental dependence into two component problems associated with source emission and noise propagation, is a useful analytic approach. Near field estimates of sound power level provide a potentially powerful experimental tool for empirically separating the problem and permitting the direct study of source emission dependence on the environment. The only potential concern is that raised in section 2.4 , $1 . e$., the question of whether in fact the source performs in the same way during stationary and 


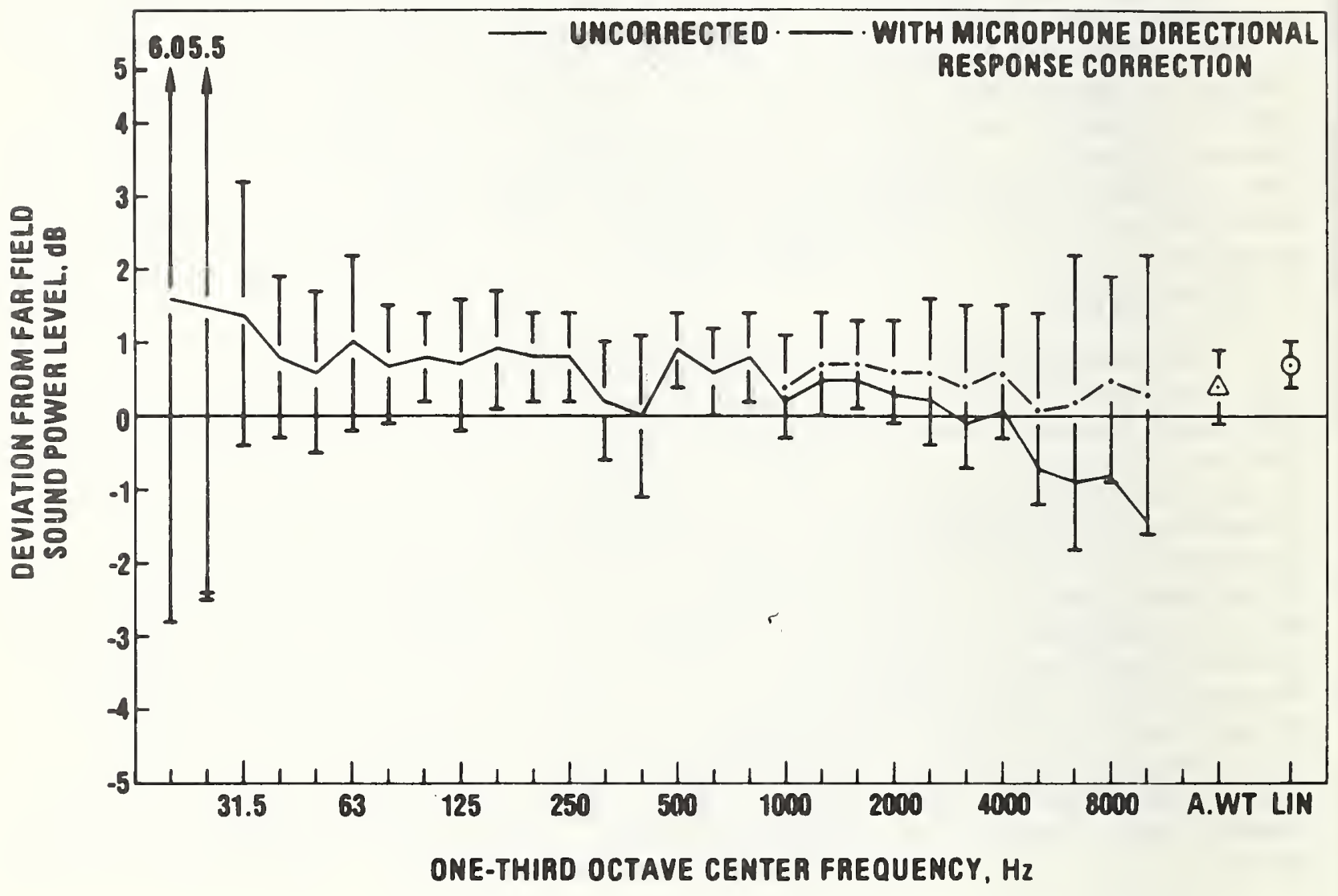

Figure 11. Plot of average deviation of near field from far field sound power level [14]. 

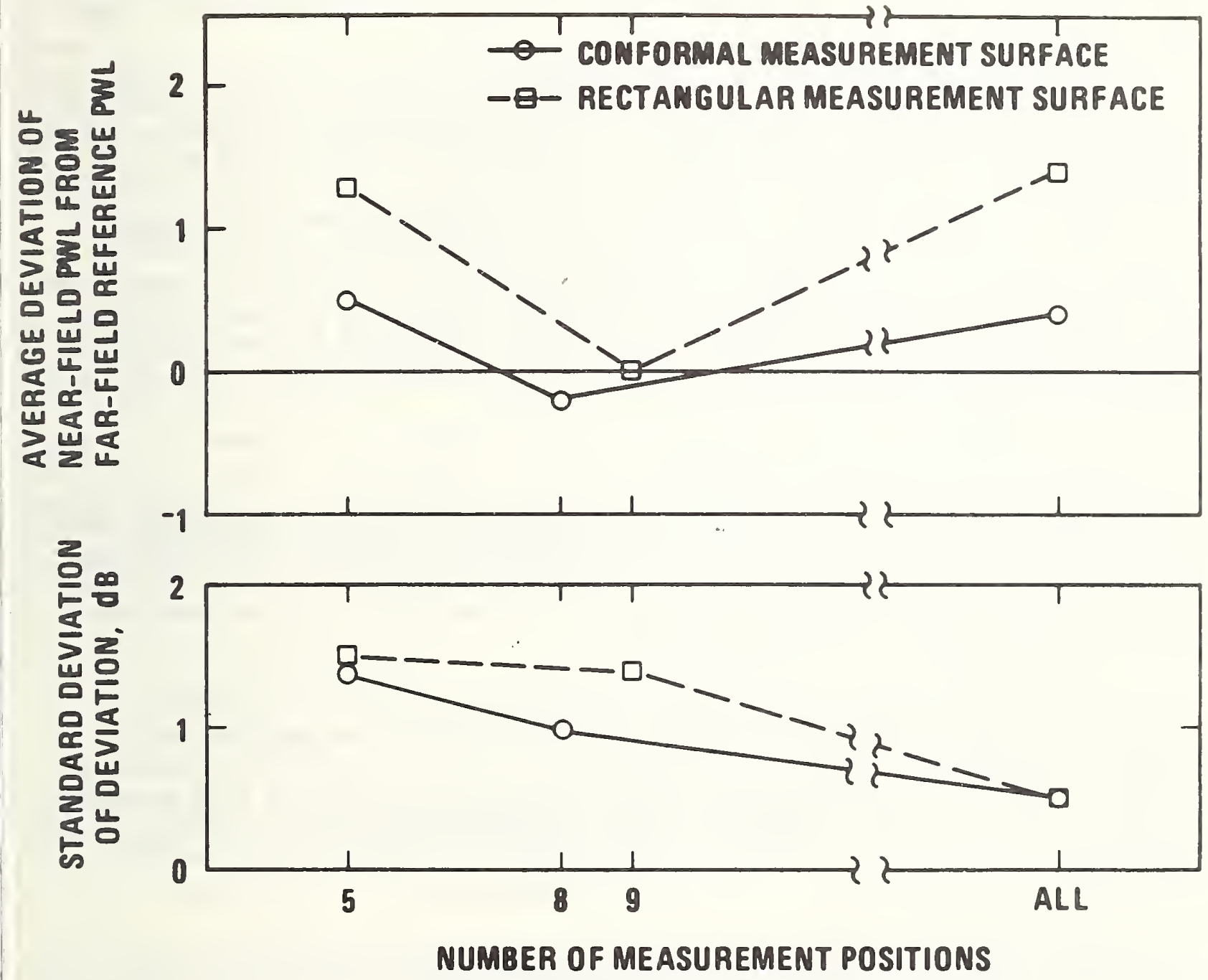

Figure 12. "Bias" and "precision" of A-weighted sound power level (PWL) vs. number of measurement positions (17 compressors) [14]. 
moving measurements. Technological problems associated with deriving a useful signal from microphones mounted on the vehicle preclude reliance on making near field measurements on the moving truck. Thus, investigating source emissions on the basis of stationary measurements appears to be the best approach.

\subsection{Statistical Aspects of the Experiment Design}

\section{a. Accuracy and Precision Considerations}

It is customary to distinguish between the accuracy of a measurement, as defined by the difference between the measurement result and some reference value and the precision of the measurement which is a measure of the internal consistency of the data. This distinction will be maintained through these discussions.

The principal objectives of the experiment involve the determination of relative changes in measurement results to a high degree of accuracy. Since the experiment involves a long time base, the only convenient way of assessing the precision of the acoustic instrumentation is through a transfer calibration to an accurately known standard (such as a pressure corrected pistonphone source). However, since the objectives involve only relative changes, and all data on specific vehicles should be reported in a normalized form, as changes from an overall average level or an arbitrary zero. This will eliminate from consideration the absolute comparison between specific vehicles, but will retain the ability to compare relative magnitudes of specific sources.

\section{b. Data Reduction and Data Analysis}

Because of the long time base of the experiment and the associated need to show preliminary results during the experiment, both for evaluating the progress of the experiment and making decisions concerning the overall test plan, it is useful to make the distinction between data reduction and the subsequent analysis of the pooled data.

In subsequent discussions these activities w111 be distinguished by refering to "data reduction" as the process of putting raw data in the form(s) suitable for later, detailed analysis and also applying preliminary analysis techniques to identify the information content of the data acquired to date. The term "data analysis" will then be used to refer to the systematic evaluation of the data in the search for underlying physical mechanisms.

For preliminary analysis, multivariate statistical techniques (principally partial correlation or path analysis[20]) should be used to identify the degree to which the observed variations of a selected principal dependent variable are in fact correlated with other variables. It is suggested that an appropriate dependent variable is the maximum A-weighted sound level at the standard (i.e., J366b) measurement position. One possible 
result from such analysis is the presentation of a regression equation and associated confidence interval estimates. These confidence interval estimates can then be used to determine when the data set is sufficiently broad so as to permit reliable identification of dependence within some a priori defined level of confidence. (A discussion of a possible form for developing such an analysis is included in Appendix A.)

A confidence interval for the actual physical coefficients $C_{\text {f ir }} a$ regression equation can be estimated, and has the typical form of

$c_{i}$ is within $\left[c_{i} \pm t_{(1-\alpha / 2, n-m)} \frac{s_{j}}{s_{i} \sqrt{n-m}}\right]$,

where $t$ is the student's $t$ statistic for the $100(1-\alpha)$ percent level of confidence, with $\mathrm{n}-\mathrm{m}$ degrees of freedom, $\mathrm{n}$ is the total number of observations of sound level; $\mathrm{m}$ is the total number of variables in the model; and $\mathrm{S}_{\text {; }}$ and $\mathrm{S}$. are the estimated standard deviations of the dependent and the ith independent variables respectively.

\section{c. Sensitivity of the Experiment}

It is extremely difficult to obtain an estimate of the actual sensitivity of the experiment to variations because of the lack of data. Thus, updates of these estimates will be an important part of the data reduction scheme. As a rough estimate, for purposes of discussion, assume $n-m>30$ and a 90 percent level of confidence so $t, 95,30^{2 t}, 95, \infty^{2} 2$. Using data from passby measurements of automobiles [2]; the nominal'spread is a $4 \mathrm{~dB}$ range in sound level for a $50^{\circ} \mathrm{C}$ range in temperature. Thus, if the measurements were concentrated near both ends of a $50^{\circ} \mathrm{C}$ band, a standard deviation of $1 \mathrm{~dB}$ in sound level and a $10^{\circ} \mathrm{C}$ standard deviation of temperature might be expected. The resulting sensitivity then is on the order of,

$$
\begin{gathered}
\pm 2 \times \frac{1 \mathrm{~dB}}{10^{\circ} \mathrm{C}}\left(\frac{1}{\mathrm{n}}\right)^{1 / 2} \\
=\frac{.2}{\sqrt{\mathrm{n}}} \mathrm{dB} /{ }^{\circ} \mathrm{C} .
\end{gathered}
$$

Present data on automobiles suggests a slope of about $0.04 \mathrm{~dB} /{ }^{\circ} \mathrm{C}$. In order to detect this with 90 percent confidence would require,

$$
\mathrm{n}=\left(\frac{.2}{.04}\right)^{2}=25 \text { measurements. }
$$

Alternatively, with, say 3 trucks, 12 passbys/truck/outing, and 6 outings the 90 percent confidence interval sensitivity for temperature dependence would be for each truck,

$$
\mathrm{S}_{\mathrm{t}}(1)=\frac{.2}{\sqrt{12 \times 6}} \sim 0.02 \mathrm{~dB} /{ }^{\circ} \mathrm{C} \text {. }
$$


If the data for three trucks are statistically indistinguishable, so that the results can be pooled, this improves to,

$$
S_{t}(3)=\frac{s_{t}(1)}{\sqrt{3}} \sim 0.01 \mathrm{~dB} /{ }^{\circ} \mathrm{C} \text {. }
$$

2.7. Objectives and Goals of a Proposed Experiment

In the previous sections we have reviewed a number of mechanisms by which the environment can produce variations in the measured driveby noise. It is the purpose of this section to pose the questions one might ask about these variations and the degree to which answers to these questions may be derived from the experiment. In so doing, we will identify the principal objectives of the experimental program, and the goals of the study.

The principal question is what is the range of variation in measured level of truck driveby noise and is it systematically dependent on observable environmental variables. This question can only be answered definitively for all trucks by an experiment on a sample representative of a11 trucks. However, we can provide a hint at the answer through the study of a few trucks and a selected group of environmental factors. To the extent that the effects are similar on these trucks and that we can identify suitable generalized physical mechanisms responsible for the observed variations, we can infer the information required in order to find a general expression for such variation. It is logical that a subsequent study of more general applicability should concentrate on the more significant variables identified in this experiment.

Thus, a first objective of this experiment should be:

1. Rank order, in terms of significance of variation induced in measured truck sound level, the principal environmental variables associated with vehicle noise measurement.

Since the rank ordering implies the effect of all potential sources of variation are considered, this implies a study in which all sources of variation are considered, or alternatively, that only those variables which are included in the study can be so ordered. The initial proposed variable catagories for study are as follows:

1. Mean temperature over a replication period.

2. Mean wind speed (component in the direction of propagation).

3. Atmospheric pressure.

4. Relative humidity.

5. Magnitude of temperature gradient.

6. Magnitude of wind gradient. 
An experimental program should seek to maximize the range of variations in these variables to the extent possible within financial limitations.

Since it is hypothesized that the above effects may be different for different source types or geometries, several different source types should be included. It is proposed that these sources should include:

1. whole truck.

2. truck fan noise (aerodynamic source).

3. truck exhaust noise (radiated from top of exhaust stack).

4. noise from radiating surfaces (presumed to remain when exhaust, fan and, if necessary, inlet noise are removed).

A second objective of the experiment should be:

2. Identify to what extent these variations are due to changes in the propagation path, and conversely to what extent they represent changes in the vehicle sound emission.

This second objective implies that some analysis or measurement procedure can be identified, which can separate these effects. It is proposed that this can be accomplished by assuming that the change in the near field estimate of sound power is a direct measure of change in vehicle emission. This test is most conveniently performed using a stationary simulation of the driveby test. Since stationary simulations of driveby tests have not previously been established as comparable with moving tests, accomplishing this objective implies a two stage test. First, establish the comparability of driveby testing with a stationary simulation of a driveby and if comparability is established, use near field measurements of a stationary vehicle to directly determine the change in vehicle emission as a function of environmental variables.

Both of the above objectives can be accomplished with a relatively limited set of acoustic and environmental measurements (e.g., A-weighted sound level measurements at standard J366b measurement positions, and at an array of microphones in the near field of the vehicle during stationary tests, plus typical measures of environmental variables such as mean wind speed and temperature at various positions on and above the test pad).

A larger question than either of the above forms the principal goal of the overall study. This question is simply what physical mechanisms are consistent with the observed variation in truck noise measurement. In order to provide a data base adequate for testing various hypotheses in this regard, it is necessary to have information of more considerable detail and extent. In particular we note that these hypotheses should result in 
experimentally verifiable predictions of changes in vehicle performance or changes in patterns (e.g., SPL vs. time, directivity or frequency spectrum) of the radiated sound. In anticipation of this, the experiment performed should provide additional data. The discussions in previous sections suggest that as a minimum this additional data should include the following:

a) Vehicle position vs. time data, for correlation with sound leve 1 vs. t1me.

b) Vehicle performance measures such as engine speed and horsepower vs. position.

c) Vehicle operational environment measures (e.g., typical temperatures and pressures at important locations in or near the engine).

d) Directivity of the vehicle (horizontal and vertical) at some position near the maximum noise point.

e) Spectrum of vehicle noise vs. time.

f) Spectrum of vehicle sound power vs. time.

g) Additional environmental data such as the detailed mean temperature and wind gradients and a measure of spatial and temporal fluctuations of these quantities.

This data base may then be used as the first testing ground for any physically based models of environmental effects.

The study will thus proceed in three principal phases. This report represents the culmination of the first phase of drawing together the available information in order to prepare a logically comprehensive experiment. The second phase consists of obtaining a set of data according to the comprehensive plan and performing a preliminary data reduction to show the superficial dependence of truck noise data on the environment. The third phase of the study consists of analyzing the resulting data in detail in order to identify and test hypotheses which explain the results of the measurements.

\section{PROPOSED EXPERIMENT}

This section describes the experimental plan developed on the basis of the technical background presented in section 2 . Sections 3.1 and 3.2 contain a brief overview of the total experiment and a description of the instrumentation and proposed test. Then in sections 3.3 and 3.4 the specific details of the tests -- moving and stationary -- are discussed.

\subsection{Overview of the Experiment}

The proposed experiment will involve the measurement of acoustic, vehicle and environmental data for a variety of vehicle and environmental 
conditions. These data will be used to determine the systematic and nonsystematic dependence of observed truck driveby noise on the environmental effects present during the measurement.

Three trucks are proposed by MVMA to be tested in the course of this experiment: two diesel powered and one gasoline powered. These vehicles will be provided by the appropriate member organizations of MVMA and will be committed solely to this project until its completion. These vehicles will be instrumented such that the necessary data to characterize their performance and noise emission (i.e., generation and radiation) can be obtained during all phases of testing. These vehicles will be operated and measurements taken for three conditions: whole truck, truck without fan, and truck without exhaust or fan and exhaust.

At the field test site two basic types of test will be performed -moving and stationary. The moving tests will be made according to the standard procedures recommended by SAE Standard J366b. In addition to the $\mathrm{J} 366 \mathrm{~b}$ microphones at 50 feet $(15.2 \mathrm{~m})$ on both sides of the vehicle, an array of microphones will be used to determine the horizontal and vertical directivity near the ground plane for truck drivebys. Two microphones will also be mounted on the vehicle during the driveby to give some near field information which may be useful in determining changes in noise emission. Concurrent with the acoustic measurements, environmental data (wind, temperature and their gradients, relative humidity and barometric pressure) and vehicle parameter data (temperatures, pressures, drive shaft speed and torque) will also be recorded.

For the stationary vehicle tests, measurements simulating the SAE J366b test will be made using moving microphones on each side of the vehicle which are traversed past the truck while the engine speed is controlled to simulate a driveby. In addition, measurements will be made for stationary run-up tests according to the procedures specified by the DOT Bureau of Motor Carrier Safety regulations for compliance with interstate motor carrier noise emission standards. For both types of tests a near field array consisting of eight microphones will be used to determine an estimate of the sound power level. Several stationary far field microphones will also be used in addition to the moving microphones. As for the moving tests, vehicle and environmental conditions will be monitored concurrently with the acoustic measurements.

To summarize, the overall test will involve three vehicles operated under three conditions using moving and stationary tests. The proposed test schedule and overall test plan are laid out in Figure 13. Five field trips, during the period December 1976 to August 1977 (an optional trip is tenatively scheduled for June), are presently planned. The first trip will run for about two weeks -- one week to become familiar with the test sites, instrumentation and vehicle operation and one week for measurements -- with the subsequent four or five trips lasting one week each. During each trip approximately 25 percent of the time will be spent on the moving tests and 


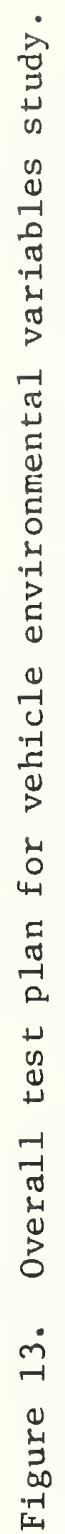

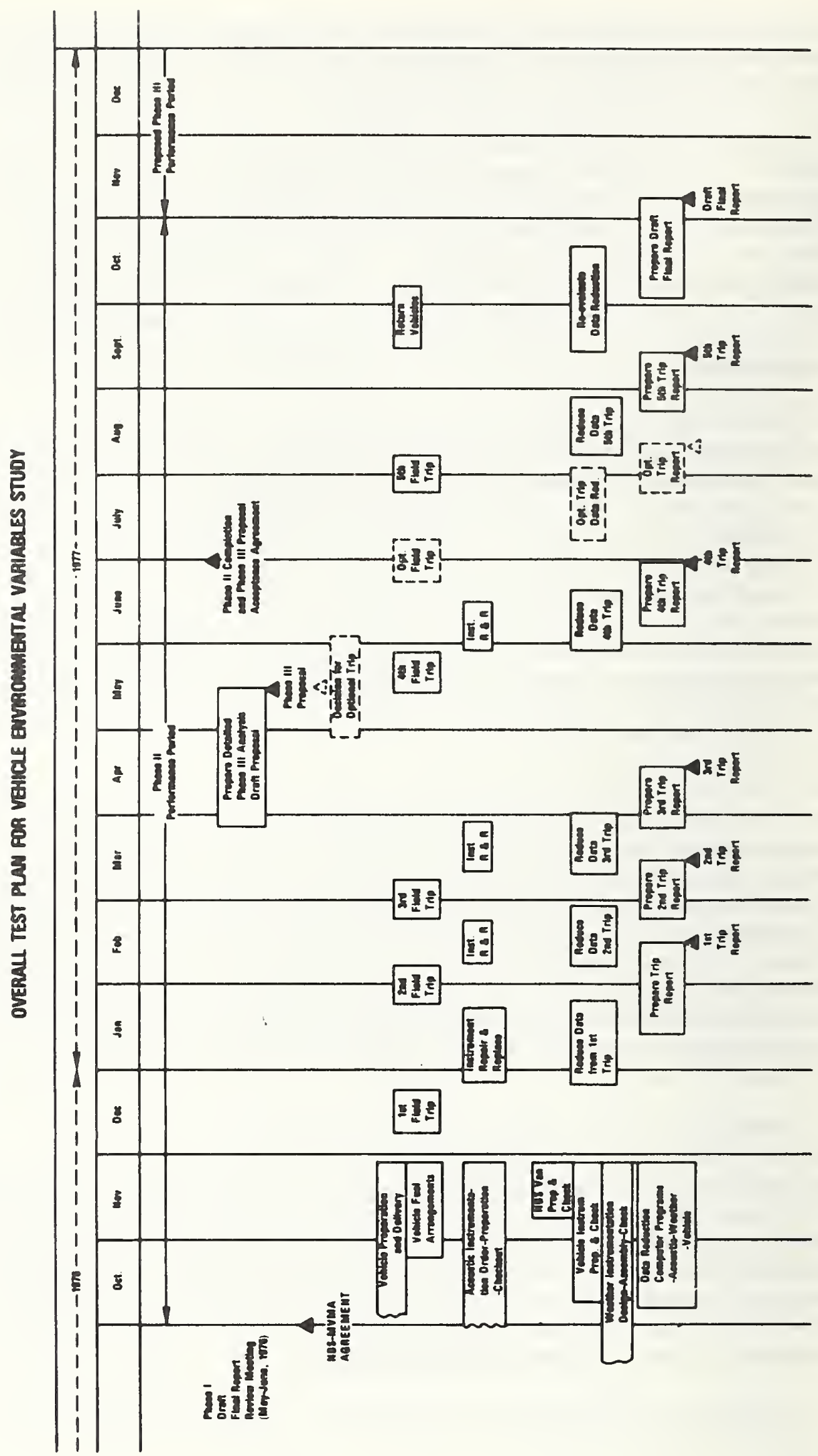


75 percent on the stationary tests. For both moving and stationary tests, measurements will be made during cool night conditions and warm day conditions so that tests will be performed with the largest possible spread of environmental variables. After each trip a preliminary reduction of the data will be performed and a trip report prepared. Phase II will then culminate with a report summarizing the data obtained during the five field trips and a proposal outlining the detailed analysis to be performed under Phase III. More explicit details of this study are presented in the remainder of section 3 .

\subsection{Hardware}

\section{a. Proposed Test Site}

The proposed test site for this study is at the International Harvester Truck Engineering Center in Fort Wayne, Indiana. This test site has the facilities to perform both $\mathrm{SAE}$ J366b driveby tests and stationary tests with moving microphones to simulate the SAE J366b procedure. These two test facilities are shown schematically in Figure 14.

\section{i. Moving Tests}

The SAE J366b driveby test site, referred to as the Sound Pad facility, consists of a single lane asphalt track approximately 1000 feet $(304.8 \mathrm{~m}$ ) long with turn-arounds on both ends. The measurement area is located midway along the track and consists of two triangular shaped asphalt pads extending 50 feet $(15.2 \mathrm{~m})$ from the centerline of vehicle travel to the microphone locations and approximately 150 feet $(45.7 \mathrm{~m})$ along both sides of the track. This particular arrangement thus allows measurements to be made for drivebys in both directions.

In an effort to reduce the wind velocity at the test site, two wind barriers have been erected near the measurement area as shown in Figure 14. These barriers are constructed of wood arranged in a slotted design which allows the wind to flow through the barrier resulting in a reduction of the mean wind velocity. The barriers are approximately 20 feet $(6.1 \mathrm{~m})$ high and are more than 100 feet $(30.5 \mathrm{~m})$ from the acceleration point, end point and microphone as specified by $\operatorname{SAE} \mathrm{J} 366 \mathrm{~b}$.

This facility is fully automated in that only the drivers and test vehicles are ordinarily at the site. The microphones and preamps used to perform J366b measurements are designed specifically for outdoor environments and remain permanently mounted at the test site year-round. To establish truck position between the acceleration and end points, a system of two lines of magnetically activated reed switches are used. Each line of switches is 200 feet $(61.0 \mathrm{~m})$ long with switches every 5 feet $(1.5 \mathrm{~m})$ and is installed inside plastic tubing set in a shallow trough 15 inches $(0.4 \mathrm{~m})$ from the roadway centerline. The reed switches are triggered by two electromagnets suspended from the front of the vehicle. The magnets are constructed such that their width defines the lateral error and if the truck is too far off 


\section{BUILDING \\ CONTAINING \\ MINICOMPUTER \\ AND CONTROLS}

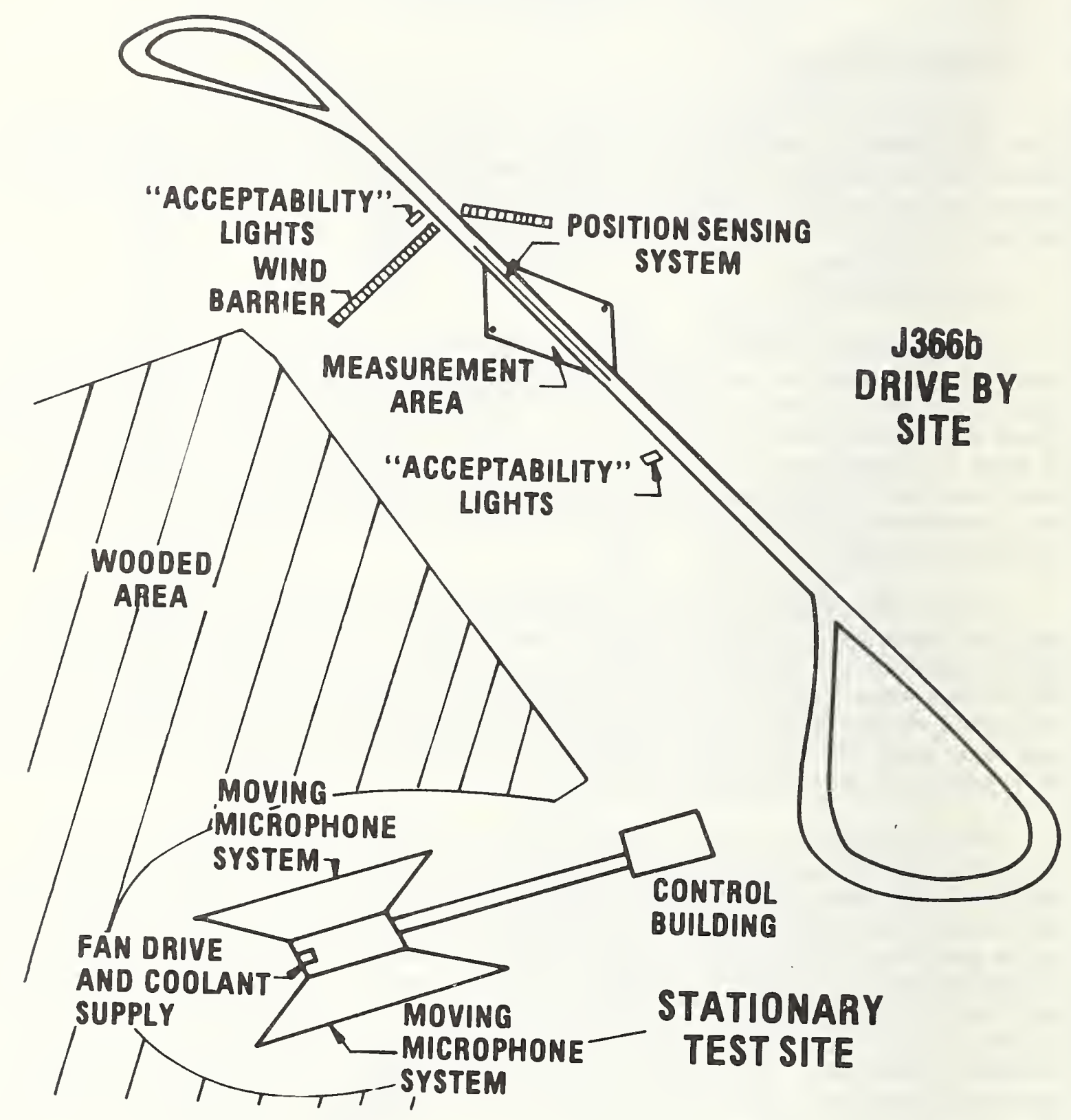

Figure 14. Schematic diagram of proposed test sites at the International Harvester Truck Engineering Center. 
center, the switches are not actuated. One electromagnet is on full-time and is used to sense vehicle position. An on-board logic system switches "on" the other electromagnet when full throttle is established and then switches it "off" when maximum rated speed is reached. In the International Harvester system, the signals from the reed switches and microphones are relayed through approximately one-half mile of cable to a central facility where the signals are analyzed using a mini-computer. The mini-computer logic is also used to send a signal to a set of "acceptability lights" at the test site which tell the driver whether it was a good run or that the vehicle did not meet the test parameters, i.e., the acceleration was before or after the acceleration point, the maximum rated speed was reached too soon or too late, the vehicle was too far off center and the reed switches were not activated by the electromagnets, or the wind velocity was too high.

\section{ii. Stationary Tests}

The stationary test site, referred to as the Source Noise Analysis Pad (SNAP), consists of a bow tie shaped asphalt and concrete test pad approximately 100 feet $(30.5 \mathrm{~m})$ wide and 150 feet $(45.7 \mathrm{~m})$ long at 50 feet $(15.2 \mathrm{~m})$ from the center point. This site is located in the center of a 300 foot $(91.4 \mathrm{~m})$ diameter circle cut of an existing woods. The purpose of locating the test pad in these woods was to provide a natural barrier against wind. The facility was designed to test a stationary vehicle (often one which isn't drivable) under conditions which would correlate very closely with the SAE J366b driveby test. To simulate this driveby test procedure, two microphones (one on each side of the vehicle located at 50 feet $(15.2 \mathrm{~m}$ ) from the center of the pad) are moved past the vehicle at a constant speed while the engine speed (or fan speed) is servo controlled (all controls are located in the building approximately 200 feet $(61.0 \mathrm{~m})$ from the pad) to correspond to the J366b engine speed/truck-microphone relative position relationship determined from an actual driveby. The driveby simulation is scaled in time such that the microphone traverse takes approximately $11 / 2$ minutes as compared to 4 or 5 seconds for an actual driveby. This time scaling is required to minimize the ambient noise of the moving microphone due to wind and noise generated by the trolley system. At a test speed of approximately 90 feet $(27.4 \mathrm{~m})$ per minute for the microphone traverse, the ambient noise level is about $55 \mathrm{~dB}$, which is more than $10 \mathrm{~dB}$ below the level of truck noise to be measured.

This facility is equipped to test vehicles in various operational modes, e.g., engine/exhaust only (no fan) to the fan only condition. The fan may be driven by an external motor located in an acoustical enclosure. For the no fan case, engine cooling is provided by bypassing the radiator with a heat exchanger of similar flow restriction and coolant pumped directly through the engine. Tests associated with engine, transmission, exhaust and intake noise utilize power absorption to provide a load for the vehicle. The power absorbers are eddy current devices that are coupled directly with the transmission. (These devices are approximately 52 inches $(1.3 \mathrm{~m})$ long and are mounted to the vehicle frame rails between the transmission and differential.) The absorbers are controlled by dc voltage and are capable of 
absorbing 350 horsepower at $2100 \mathrm{rpm}$ for approximately 20 minutes. The load capability can be increased to 500 horsepower at $350 \mathrm{rpm}$ but the test time is limited to 6 minutes due to overheating of the bearings.

In general, International Harvester personnel will be utilized for both moving and stationary tests. In particular IH will provide experienced drivers for the J366b tests and technicians to operate the microphone/engine speed servo controls at the stationary test pad. Two fuel tanks - gasoline and diesel fuel -- will be provided at the test site and maintained for use only by the vehicles in this study. Vehicle mechanics and any necessary maintenance time will also be provided by IH. NBS will provide technicians to maintain and repair test equipment which is brought to the test site and also any photographic services necessary to document the test site layout, equipment and vehicles.

\section{iii. Environmental Conditions}

As outlined in the overall test schedule, five or six field trips will be made between December 1976 and August 1977. For this period, the weather at the International Harvester test site will vary over a wide range of environmental conditions. The meteorological data for 1974 and the normal mean and extreme values based on records for the 1941 to 1970 period are given in Table 1.

On the average the daily temperatures range through an amplitude of about $20^{\circ} \mathrm{F}\left(11.1^{\circ} \mathrm{C}\right)$ between low and high, and the seasonal range is from a daily winter minima of about $20^{\circ} \mathrm{F}\left(-6.7^{\circ} \mathrm{C}\right)$ to the daily summer maxima near $85^{\circ} \mathrm{F}\left(29.4^{\circ} \mathrm{C}\right)$. Since these temperatures are based on averages, an overall temperature range of 10 to $90^{\circ} \mathrm{F}\left(-12.2\right.$ to $\left.32.2^{\circ} \mathrm{C}\right)$ could be expected during the planned field trips.

The prevailing wind directions are from the west and southwest and the average annual velocity is just slightly more than $10 \mathrm{mph}(16.1 \mathrm{~km} / \mathrm{hr})$ [measured at 20 feet $(6.1 \mathrm{~m})$ above the ground surface]. For the period December to August, the mean wind speeds range from a low of $7.7 \mathrm{mph}$ (12.4 $\mathrm{km} / \mathrm{hr}$ ) in August to a high of $11.5 \mathrm{mph}(18.5 \mathrm{~km} / \mathrm{hr})$ in January and February.

Precipitation, normally near 36 inches (914.4 mm) a year, is well distributed from January to December. The average precipitation from December to August is 3.08 inches $(78.3 \mathrm{~mm})$ per month. The mean number of days of precipitation [0.01 inches $(0.25 \mathrm{~mm})$ or more] range from a low of 8 days in August to a high of 13 days in December. The mean number of days of snow or ice pellets [1.0 inch $(25.4 \mathrm{~mm})$ or more] is zero from May to August and 1 to 2 days from December through April.

Based on these meteorological data, delays in testing due to precipitation should be minimal (i.e., not more than an average of say 20 percent of field time) and the wide range of weather conditions should provide a good basis for determining the effects of environment on truck noise measurements. 

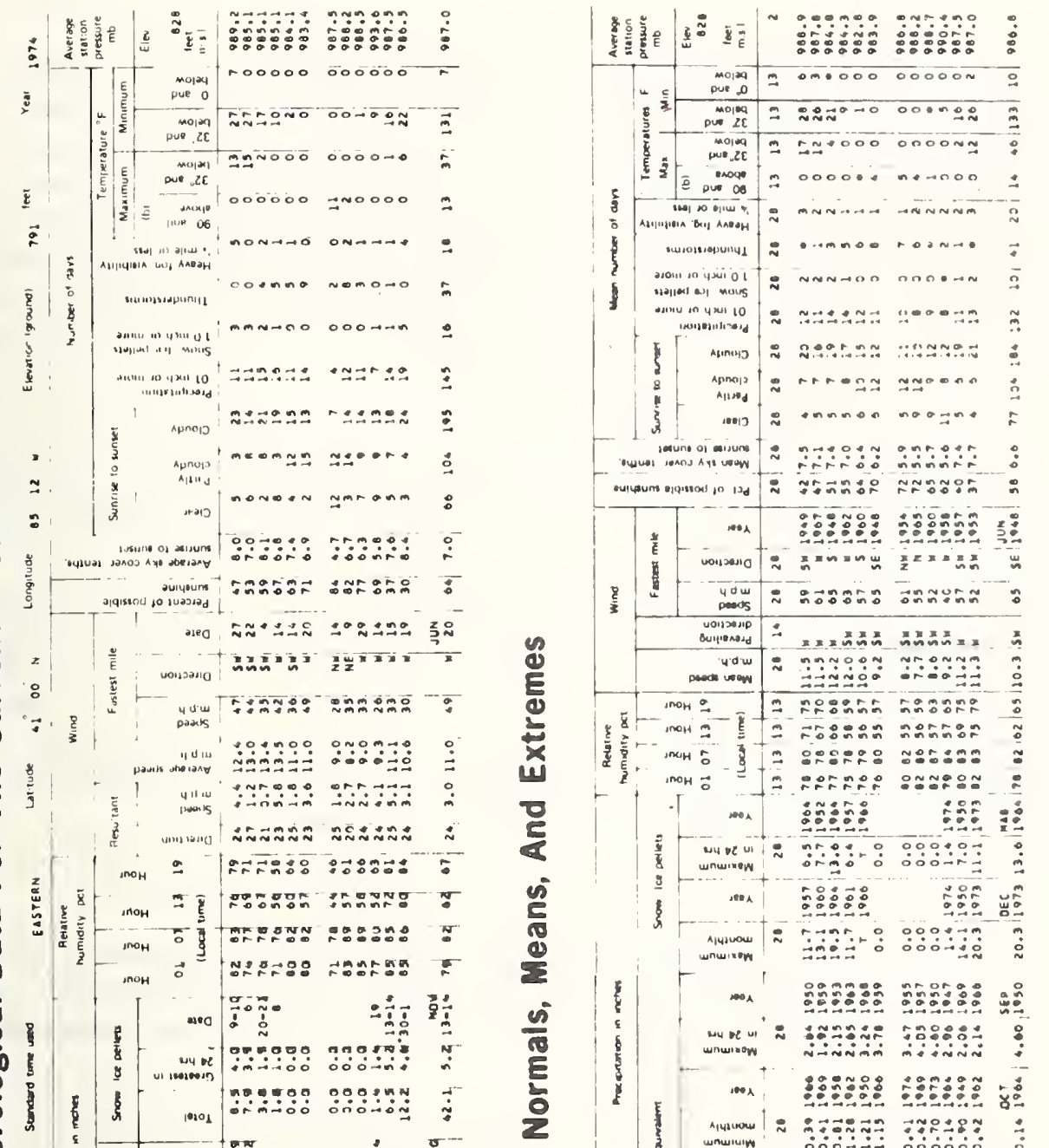

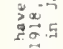

|

0
0
0

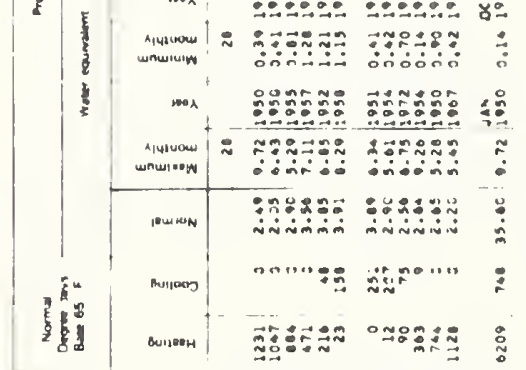

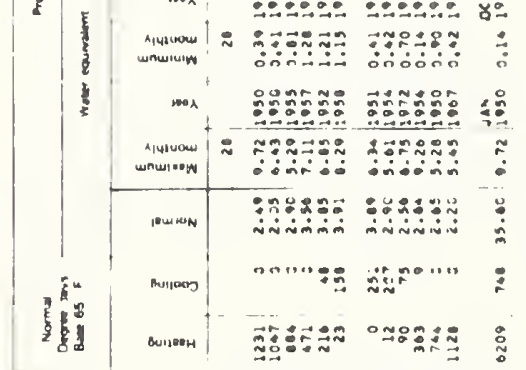

象是

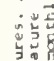

等

影

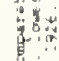

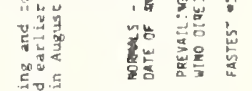

造

学 㟧

m.

1
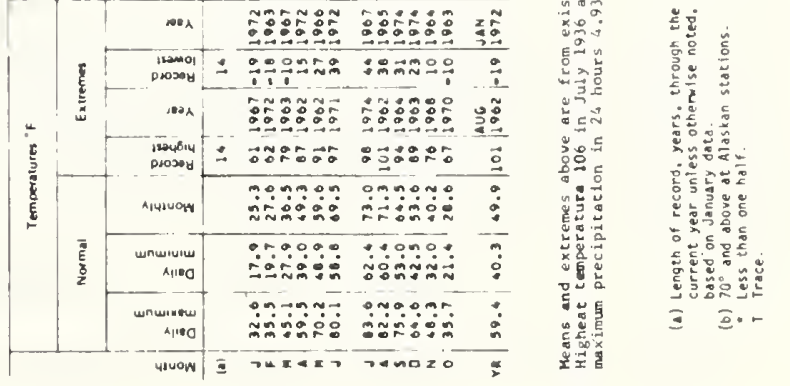


\section{b. Proposed Vehicles}

MVMA has previously arranged for vehicles to be supplied for use in this program. It is expected that the three trucks to be used will include two cab-over-engine turbocharged, diesel-powered trucks, and one gasoline powered truck of undetermined cab configuration. In order to simplify later analysis, and to reduce time involved in altering vehicle configuration during the testing phase, there are a number of particular specifications which would be highly desirable for incorporation into the test vehicles prior to delivery. These specifications are listed below followed by a discussion of the rationale for these requests:

1. Cab-over-engine configuration .

2. Engine inlet air drawn from outside the vehicle through a side or snorkle configuration.

3. Single vertical exhaust above the cab.

4. Fan with positive clutch.

5. Adequate propeller shaft length and clearance between side rails to accomodate the proposed dynamometer.

6. Vehicle parameter transducers installed.

The cab-over-engine configuration was selected not because of particular virtue, but because it is believed that a similar layout of sources and overall shape on all three vehicles would simplify the comparison between vehicles for the purposes of this study.

The principal reason for requesting engine inlet air be drawn from outside is to simplify the evaluation, and if necessary, the control of this particular source in order to permit clear identification of fan, exhaust and engine casing radiated noise. Further, an outside (i.e., not within the engine compartment) air intake permits the assumption that the temperature and pressure of inlet air are comparable with that of the ambient environmental conditions measured for reference purposes.

For the same reasons that the cab-over-engine configuration is requested, i.e., simplified analysis and comparability, the single vertical exhaust is preferred. Further, however, the assymetry of the typical single exhaust will provide a useful variation in the source geometry from the other centrally located sources. Finally, since interaction with vehicle turbulence has been hypothesized as a possible mechanism for difference between stationary and moving tests, the fact that the vertical exhaust is not in the slip-stream of the truck body should minimize this effect.

The use of a positive fan-clutch permits convenient engagement and dis- 
engagement of the fan and positive speed control (i.e., some particular ratio times engine speed) during "fan on" studies.

Figure 15 shows the space requirements for the dynamometer system to be used in the stationary tests. In order to facilitate dynamometer installation it is requested that the forward rear axle be positioned to provide the clearance indicated in the figure plus some reasonable assembly clearance. If necessary, on short frame, dual rear axle vehicles this can of course, be accomplished by removing the forward axle of the pair, and providing an appropriate length propeller shaft to reach the aft rear axle. For each vehicle, it would also be preferrable to remove the fifth wheel and intermediate side rall braces in order to provide space above and between the frame rails for clear installation of the dynamometer. Since the vehicle will not be required to carry or pull a load during these tests, and these modifications are not expected to produce significant changes in low speed noise, they are judged to have no influence on the measurements.

During a recent meeting of the MVMA Vehicle Sound Level Committee, a list of vehicle parameters was derived for which monitoring was believed necessary in order to evaluate changes in the vehicle operation and performance. This list includes:

1. Engine speed derived from a non-contacting drive shaft pickup.

2. Shaft torque derived from a strain guage bridge on the drive shaft through slip rings.

3. Inlet air pressure (after turbocharger).

4. Exhaust gas static pressure before turbocharger.

5. Inlet air temperature (after turbocharger).

6. Exhaust gas temperature at top of exhaust stack.

7. Exhaust gas temperature at exhaust manifold.

8. Engine compartment air temperature.

9. Engine cooling water out temperature.

It is proposed that the vehicle supplier obtain and install transducers for these variables, wired to a common junction box to be supplied by NBS. Recommended transducers are discussed in section 3.2.c.3 under vehicle parameter data acquisition system.

\section{c. Data Acquisition and Reduction Systems}

The four major systems to be discussed here are the acquisition systems for acoustic, environmental and vehicle parameter data and the data reduction system to be used for all acquired data. 
CENTER OF

TRANSMISSION

\title{
U-JOINT
}

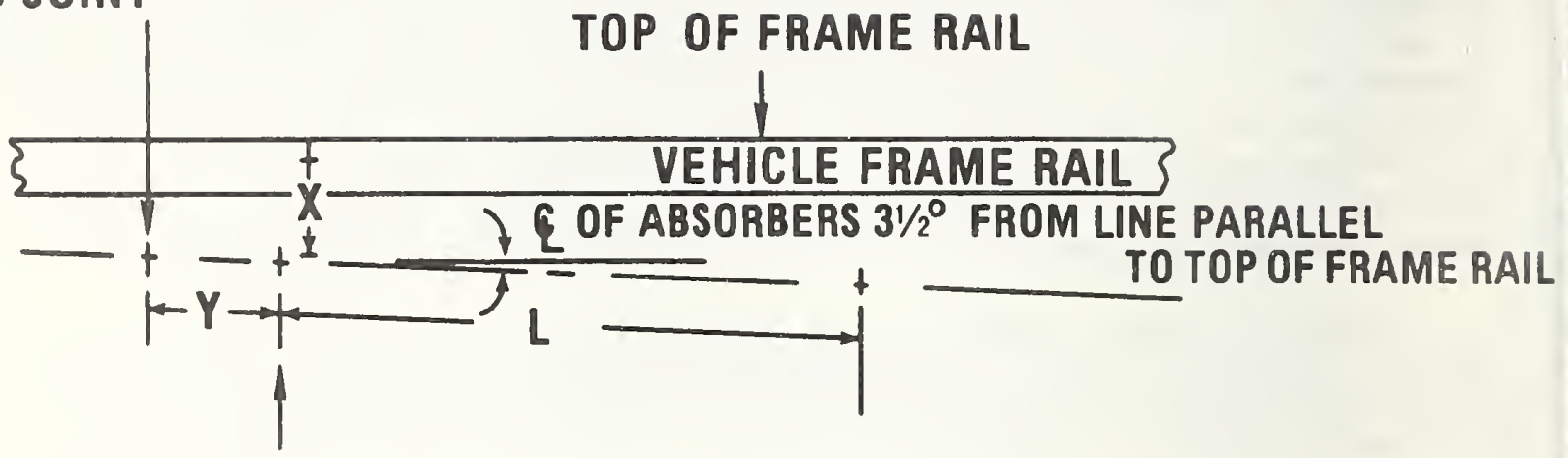

CENTER OF U-JOINT AT

FRONT OF ABSORBERS

\author{
$\mathrm{L}=$ Total length of (2) absorbers $=51.5$ inches $(1.31 \mathrm{~m})$. \\ $X=6$ to 13.5 inches $(0.15 \mathrm{~m}$ to $0.34 \mathrm{~m})$ vertical range of centerline adjust- \\ ment for propeller shaft - absorber alignment. \\ $\mathrm{Y}=$ Propeller shaft length (to be prepared at test site). \\ $=6$ inches $(0.15 \mathrm{~m})$ minimum for $7-c$ propeller shaft. \\ $=12$ inches $(0.30 \mathrm{~m})$ minimum for 1700 propeller shaft.
}

Figure 15. View of typical dynamometer mounting showing the necessary space requirements. 
1. Acoustic data acquisition. The acoustic data acquisition system will consist of a 14 channel instrument quality tape recorder configured with one digital channel and 13 IRIG intermediate band FM channels for recording time-varying data. Operated at 15 ips this system will provide $0-10 \mathrm{kHz}$ bandwidth with nominally $50 \mathrm{~dB}$ signal to noise ratio. The acoustic transducers will include $1 / 2$ inch back vented condenser microphone cartridges with dehumidifier sections, preamplifiers and battery operated power supplies. For signal monitoring, an oscilloscope, real time analyzer and audio channel will be provided. During moving tests, data from two microphone positions fixed on the vehicle will be transmitted to the acoustic acquisition sys tem through a two channel FM telemetry system with $5 \mathrm{kHz}$ bandwidth and $30 \mathrm{~dB}$ dynamic range. The digital channel will encode a header incorporating test identification information, time-of-day clock information for relating data from other systems to this data, and vehicle or microphone positioning data derived from existing transducers at the test site.

2. Environmental data acquisition. The environmental data to be determined include: ambient air temperature and wind speed and their respective gradients in the region within about five meters of the test pad surface, wind direction, pad surface temperature, relative humidity and barometric pressure. To accomplish the wind and temperature measurements and provide information on spatial variation of these data, two 5 meter towers will be constructed on which hot wire thermoanemometers will be mounted at appropriate intervals for determining estimates of temperature and wind gradients. A total of six or seven thermoanemometers are anticipated for each tower. The data from these transducers will be multiplexed and logged together with time of day, wind direction and surface temperature on portable digital data loggers. A complete set of these will be multiplexed and logged every 5-15 seconds to provide nominally 50 sets of data during each complete set of replications of driveby data. Relative humidity and pressure data will be determined from analog instrumentation and logged on the acoustic data reader.

3. Vehicle parameter data. The vehicle parameter data will be recorded on IRIG standard intermediate band format using a 14 channel tape recorder configured for $13 \mathrm{FM}$ channels with nominal $100 \mathrm{~Hz}$ bandwidth using the 14th channel in digital format to record time of day and vehicle identification.

The transducers for vehicle parameter data, to be provided and installed by the vehicle suppliers, fall into two categories, including temperature and other parameters.

The temperature transducers consist of Type $\mathrm{E}^{-2 /}$ chromel-constantan thermocouples (nominally 90 percent $\mathrm{Ni}, 10$ percent $\mathrm{Cr}$ vs. 55 percent $\mathrm{Cu}, 45$ percent $\mathrm{Ni}$ ) in order to monitor the following temperatures:

$\underline{2} /$ The letter designation is that recommended by ASTM Committee E-20. 
1. Inlet air temperature (after turbocharger or prior to carburator).

2. Engine cooling water temperature out of the block.

3. Engine compartment air temperature.

4. Exhaust gas temperature at exhaust manifold (prior to turbocharger).

5. Exhaust gas temperature at top of stack.

Leads from these thermocouples and other transducers should be electrically insulated, mechanically secured, and run to a terminal strip in a constant temperature "zone box" to be supplied by NBS. Cable connections from this box, to the signal conditioning and recorder package, as well as a reference thermocouple, will be provided by NBS.

The remaining vehicle parameters to be sensed include:

1. Engine speed.

2. Shaft torque.

3. Engine air inlet pressure (turbocharged only).

4. Engine exhaust pressure.

The engine speed detector can be of any noncontacting type which produces a well defined number of pulses per engine revolution (consistent with a $100 \mathrm{~Hz}$ bandwidth limitation). This transducer can operate on any shaft or gear whose rotational speed is directly relatable to engine and propeller shaft. speeds.

Propeller shaft torque can be most expeditiously determined with a bonded strain gage bridge mounted on the shaft with voltages carried through a set of slip rings mounted on the transmission or differential. Electrical connections should permit easy removal of the propeller shaft for stationary tests. NBS will provide a controlled nominal 10 volt dc source for energizing the strain gage bridge.

Transducers for the pressure measurements have not yet been selected, since the question of differential vs. absolute pressures is as yet unresolved. NBS will provide, in this system, stabilized dc amplifiers for signal conditioning.

We note in conclusion that power for the tape recorder will also be required from the vehicle electrical system during engine operation. Recommendations for wiring and electrical connection points for nominal $12 \mathrm{v} d c$, 400 watts will be required. 
4. Data Reduction. All data collected from the above systems will be converted where necessary to digital format and stored in a form directly accessible by computer at NBS. Acoustic data will be reduced on a one-third octave band real time analyzer in $100 \mathrm{~ms}$ time intervals as a first approximation to fast response of a sound level meter. Position data will be coded to give positions vs. time information. Environmental data will be averaged to give mean and variance information at each measurement location over a suitably short time interval. Vehicle parameter data will be speed scaled and digitized (with an $\mathrm{ADC}$ ) for use in generating plots of parameters vs. time or position.

\subsection{Moving Tests}

In this section we review and discuss the specifics of the proposed moving tests.

\section{a. Test parameters}

Figure 16 shows a detailed schematic view of the proposed test site and microphone arrangements. It is expected that the site will be used in a bi-directional mode, which implies that the microphone arrays must be symetrically disposed to the left and right of a common line, in order to produce comparable data in each direction. The line selected for this disposition is the line connecting the standard J366b microphone positions (shown as solid circles on the figure).

Two microphone arrays for evaluation of directivity are planned, one in the horizontal plane and one in the vertical plane through the line of symmetry. The microphones will be arranged at $\pm 30^{\circ}$ and $+60^{\circ}$ from the line through the $\mathrm{J} 366 \mathrm{~b}$ microphones. Changes in horizontal directivity data are expected to provide information suitable for testing hypotheses about the systematic effects of wind and wind gradient components perpendicular to the direction of vehicle travel. The height to be used for this array is $1.2 \mathrm{~m}$ (i.e., 4 feet, same as the J366b microphones). The vertical directivity array, is intended to provide information with which to test analytic models of the effect of temperature, temperature gradient, wind and wind gradient on the transmission function from the vehicle to the J366b microphones. Thus only the region within a few meters of the J366b microphones will be studied. The proposed microphone heights for this array include 0 (ground plane), 0.6 , 1.2 (J366b microphone), 2.0, and 4.0 meters. Data from this array can also be used to directly evaluate environmental effects on alternate microphone heights to the J366b position.

It is expected that comparability between stationary and moving tests will be established through analyses of $\mathrm{J} 366 \mathrm{~b}$ microphone data. In order to provide additional data points for such a comparison, and further, to provide an alternative check for the study of changes in vehicle emission, two near field measurement positions are planned to be fixed with the vehicle. While it is highly doubtful that these two positions will provide sufficient 


\section{MOVING VEHICLE TESTS}

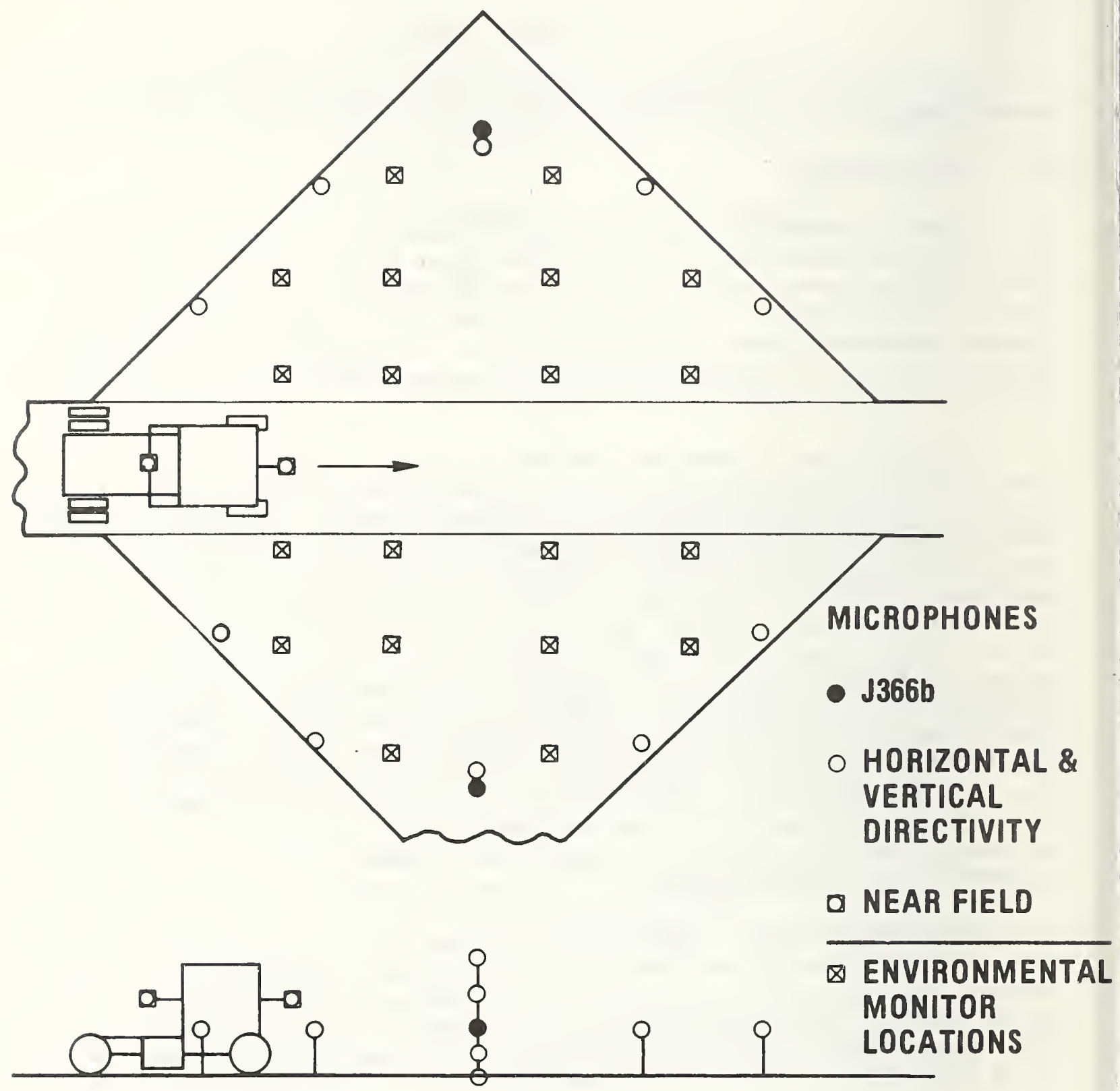

Figure 16. Schematic diagram for moving vehicle test site showing transducer array locations. 
information to permit adequate study of this problem in themselves (particularly when wind noise problems and dynamic range limitations of state-of-the-art telemetry systems are considered) it is felt that the two positions represent an acceptable compromise between information desired, and financial constraints. These measurement positions will be selected to correspond directly with measurement positions in the stationary test near field array. It is expected that the positions will be those nearest the vehicle fore-aft centerline in order to have positions which relate closely with fan/engine noise and exhaust/transmission noise sources, but it is expected that this will not be firmly established until after preliminary measurements.

Vehicle positioning information and operational parameter data will be determined from the existing position sensing equipment at the test site and encoded on the digital channel. Control (i.e., acceptance or refection of the test for meeting $\mathrm{J} 366 \mathrm{~b}$ requirements with regard to vehicle acceleration point, maximum engine speed point and lateral positioning error) will be determined from the existing logic system. The normally acceptable range of vehicle positioning with respect to acceleration and end zones will be used in order to include their effect in the test variability determination.

It is proposed that prior to and at the end of a set of measurements, environmental data will be recorded at a selected representative group of positions to assess spatial variation of wind and temperature, but that during a group of measurements on a vehicle the environmental transducer towers will be operated at specific sites determined from prior surveys.

Test site acoustic evaluation measurements will be made during a time when environmental conditions (notably wind and temperature gradients) are most conducive to measurement of test pad properties. These measurements (as yet undefined, but probably consisting of determination of transmission function from several fixed source heights to particular microphone positions) will be made with the specific objective of determining that the test pad flatness and acoustic impedance for near grazing incidence has not altered significantly from previous evaluations. This investigation is expected to provide a data base from which test procedures for site qualification may also be studied.

\section{b. Test Plan for Moving Tests}

Based on recommendations from personnel in the Applied Mathematics Division, Statistical Engineering Section at NBS, the schedule for testing will be arranged in such a manner that the possibilities of systematic biasing of the data will be minimized. To assure this, the order in which the tests are performed will be randomized as much as feasible, considering the limitations of setting up and calibrating instrumentation and changing vehicle configurations. The controlled variables in the test are:

1. Vehicles: I, II, III 
2. Vehicle configurations: A - whole truck

B - without fan

C - without exhaust or fan and exhaust

3. Microphone arrays: horizontal, vertical

4. Vehicle direction: east, west

5. Time of day: day, night

For the purposes of this study, day is defined as the time period when the temperature gradient is a maximum due to the heating of the test pad (e.g., 1:00 to 5:00 p.m.) and night as the time period when the temperature gradient is a minimum (late evening or early morning).

A typical test plan, which would be completed in one calendar day and repeated during each of the five (or six) field trips, is outlined in Table 2. Also given in this table is an estimate of the time required for each test. For each test condition there are a minimum of 6 drivebys -- 3 in the east direction and 3 in the west direction alternating east, west, east, etc. Using this test plan the order of testing the individual vehicles, vehicle configurations and horizontal versus vertical microphone arrays will each be randomized for a test day. Further randomization, such as intermixing the vehicles or microphone array configurations, would be too time consuming and thus is not considered feasible in this test plan. This test plan represents the approximate schedule that will be followed during the second week of the first trip and a11 subsequent trips.

During the first week of the first trip one day will be spent in setup and checkout of equipment and site evaluation measurements. The second day will be used to record drivebys of one vehicle using all three configurations during both the day and night conditions to evaluate the test procedure. In addition, measurements will be made to verify that all three vehicles generate the maximum noise during driveby accelerations rather than decelerations. The remainder of the week will be used to prepare for the stationary tests.

\subsection{Stationary Vehicle Tests}

\section{a. Test Parameters}

Figure 17 shows a schematic diagram indicating the locations for transducers for these tests. As has already been mentioned, there are two phases to the stationary tests -- simulated drivebys and stationary run-ups. The simulated driveby is to be operated as a time scaled simulation of the J366b driveby, with engine speed controlled, at full throttle, with loading in order to preserve the engine speed/truck-microphone geometry relationship of the driveby. This relationship will be derived from the IH driveby test facility data, supported by the vehicle parameter data determined from NBS recordings. One major unknown at this juncture is the accuracy achievable in 
Table 2. Test Plan for $J 366 \mathrm{~b}$ driveby tests giving the order of vehicle testing.

\begin{tabular}{|c|c|c|c|c|c|}
\hline $\begin{array}{l}\text { Time of } \\
\text { Day }\end{array}$ & $\begin{array}{l}\text { Microphone Array } \\
\text { Configuration }\end{array}$ & $\begin{array}{l}\text { Test } \\
\text { Vehicle }\end{array}$ & $\begin{array}{l}\text { Test Vehicle } \\
\text { Configuration }\end{array}$ & \multicolumn{2}{|c|}{$\begin{array}{l}\text { Estimated Time for Set } \\
\text { Up or for } 6 \text { Drivebys } \\
\text { ( } 3 \text { East and } 3 \text { West) }\end{array}$} \\
\hline \multicolumn{4}{|c|}{ Initial Set Up and Calibration } & \multicolumn{2}{|c|}{1 hour } \\
\hline DAY & HORIZONTAL & $\begin{array}{l}\text { I } \\
\text { II } \\
\text { III }\end{array}$ & $\begin{array}{l}\text { A } \\
\text { B } \\
\text { C } \\
\text { B } \\
\text { C } \\
\text { A } \\
\text { B } \\
\text { A } \\
\text { C }\end{array}$ & $\left.\begin{array}{ll}6 & \text { minutes } \\
6 & \text { minutes } \\
6 & \text { minutes }\end{array}\right\}$ & $\begin{array}{l}1 / 2 \text { hour } \\
1 / 2 \text { hour } \\
1 / 2 \text { hour }\end{array}$ \\
\hline \multicolumn{4}{|c|}{ Change Microphone Array and Calibration } & \multicolumn{2}{|c|}{$1 / 2$ hour } \\
\hline DAY & VERTICAL & $\begin{array}{l}\text { I I I } \\
\text { I I } \\
\text { I }\end{array}$ & $\begin{array}{l}\text { C } \\
\text { A } \\
\text { B } \\
\text { C } \\
\text { B } \\
\text { A } \\
\text { B } \\
\text { A } \\
\text { C }\end{array}$ & $\left.\begin{array}{ll}6 & \text { minutes } \\
6 & \text { minutes } \\
6 & \text { minutes } \\
6 & \text { minutes } \\
6 & \text { minutes } \\
6 & \text { minutes } \\
6 & \text { minutes } \\
6 & \text { minutes } \\
6 & \text { minutes }\end{array}\right\}$ & $\begin{array}{l}1 / 2 \text { hour } \\
1 / 2 \text { hour } \\
1 / 2 \text { hour }\end{array}$ \\
\hline \multicolumn{4}{|c|}{$\begin{array}{l}\text { Disassembly of Instrumentation to Protect Against Damage } \\
\text { During Time Allowed for Environmental Varlables to Change }\end{array}$} & Minimum & 4 hours \\
\hline \multicolumn{4}{|c|}{ Instrumentation Set Up and Calibration } & \multicolumn{2}{|c|}{1 hour } \\
\hline NIGHT & VERTICAL & $\begin{array}{l}\text { II } \\
\text { I I I } \\
\text { I }\end{array}$ & $\begin{array}{l}\text { C } \\
\text { A } \\
\text { B } \\
\text { A } \\
\text { B } \\
\text { C } \\
\text { B } \\
\text { C } \\
\text { A }\end{array}$ & $\left.\begin{array}{ll}6 & \text { minutes } \\
6 & \text { minutes } \\
6 & \text { minutes } \\
6 & \text { minutes } \\
6 & \text { minutes } \\
6 & \text { minutes } \\
6 & \text { minutes } \\
6 & \text { minutes } \\
6 & \text { minutes }\end{array}\right\}$ & $\begin{array}{l}1 / 2 \text { hour } \\
1 / 2 \text { hour } \\
1 / 2 \text { hour }\end{array}$ \\
\hline \multicolumn{4}{|c|}{ Change Microphone Array and Calibration } & \multicolumn{2}{|c|}{$1 / 2$ hour } \\
\hline NIGHT & HORIZONTAL & $\begin{array}{l}\text { I I I } \\
\text { I } \\
\text { I I }\end{array}$ & $\begin{array}{l}\text { B } \\
\text { C } \\
\text { A } \\
\text { C } \\
\text { B } \\
\text { A } \\
\text { A } \\
\text { B } \\
\text { C }\end{array}$ & $\left.\begin{array}{ll}6 & \text { minutes } \\
6 & \text { minutes } \\
6 & \text { minutes } \\
6 & \text { minutes } \\
6 & \text { minutes } \\
6 & \text { minutes } \\
6 & \text { minutes } \\
6 & \text { minutes } \\
6 & \text { minutes }\end{array}\right\}$ & $\begin{array}{l}1 / 2 \text { hour } \\
1 / 2 \text { hour } \\
1 / 2 \text { hour }\end{array}$ \\
\hline
\end{tabular}


the control loop, and whether it is desirable or relevant to consider small systematic changes in this speed control relationship which may occur during the total perfod of the test. This question can only be resolved based on experience with the equipment.

For the stationary run-up tests the movable microphones w111 be fixed either at the beginning of the trolley system (ready to start the next driveby simulation) or at the midpoint on the trolley where they will be used as the 50 foot $(15.2 \mathrm{~m})$ microphones if the far field microphones are not available.

As was previously noted, the stationary test site is surrounded on three sides by trees at about a 150 foot $(45.7 \mathrm{~m}$ ) radius. It is expected that this will produce relatively unusual wind conditions compared to the more common open driveby site. To the extent that wind is interrelated with temperature and temperature gradient these factors will also be altered. The significance of these variations is presently indeterminate since there is no comparable data for these effects on this or other sites. Thus, this question also will not be resolvable until well into this experiment.

The J366b microphone positions used in these tests will use existing traversing equipment and electronics. The microphone cartridges for these channels as well as system electrical calibration (i.e., gain and frequency response) will be supplied by NBS.

The need for near field measurements is one of the principal reasons for performing the stationary tests. It is thus not surprising that the majority of the available acoustic channels are devoted to this function. The eight microphone array shown schematically in Figure 17 is that studied during a previous program on measurements of portable air compressor noise[14] (see section 2.5., Figures 11 and 12). This array apparently provides nominally zero bias and measurement imprecision of on the order of $1 \mathrm{~dB}$, for estimation of far field sound power from large rectangular sources.

The coordinates of the array positions are given in a draft ISO standard[21], and are reproduced in Figure 18 and Table 3. The actual positions depend on the physical size of the source. The positions are determined with respect to a reference parallelepiped which just encloses the source. For a cab-over-engine truck with a transmission that does not extend substantially beyond the cab plan dimensions, this reference surface will be the smallest rectangular box which just encloses the cab. Assuming the overall dimensions of such a box would be say $3 \mathrm{~m}$ wide by $2.5 \mathrm{~m}$ long $\mathrm{x} 3.5 \mathrm{~m}$ high, and a measurement radius of 1 meter the corresponding microphone location dimensions would be (see Table 3):

$$
\begin{aligned}
& \mathrm{a}=2.5 / 2+1=2.25 \mathrm{~m} \\
& \mathrm{~b}=3 / 2+1=2.5 \mathrm{~m} \\
& \mathrm{~h}_{1}=1 / 2(2.25+2.5-1 / 2)=2.125 \mathrm{~m}
\end{aligned}
$$




\section{STATIONARY VEHICLE TESTS}
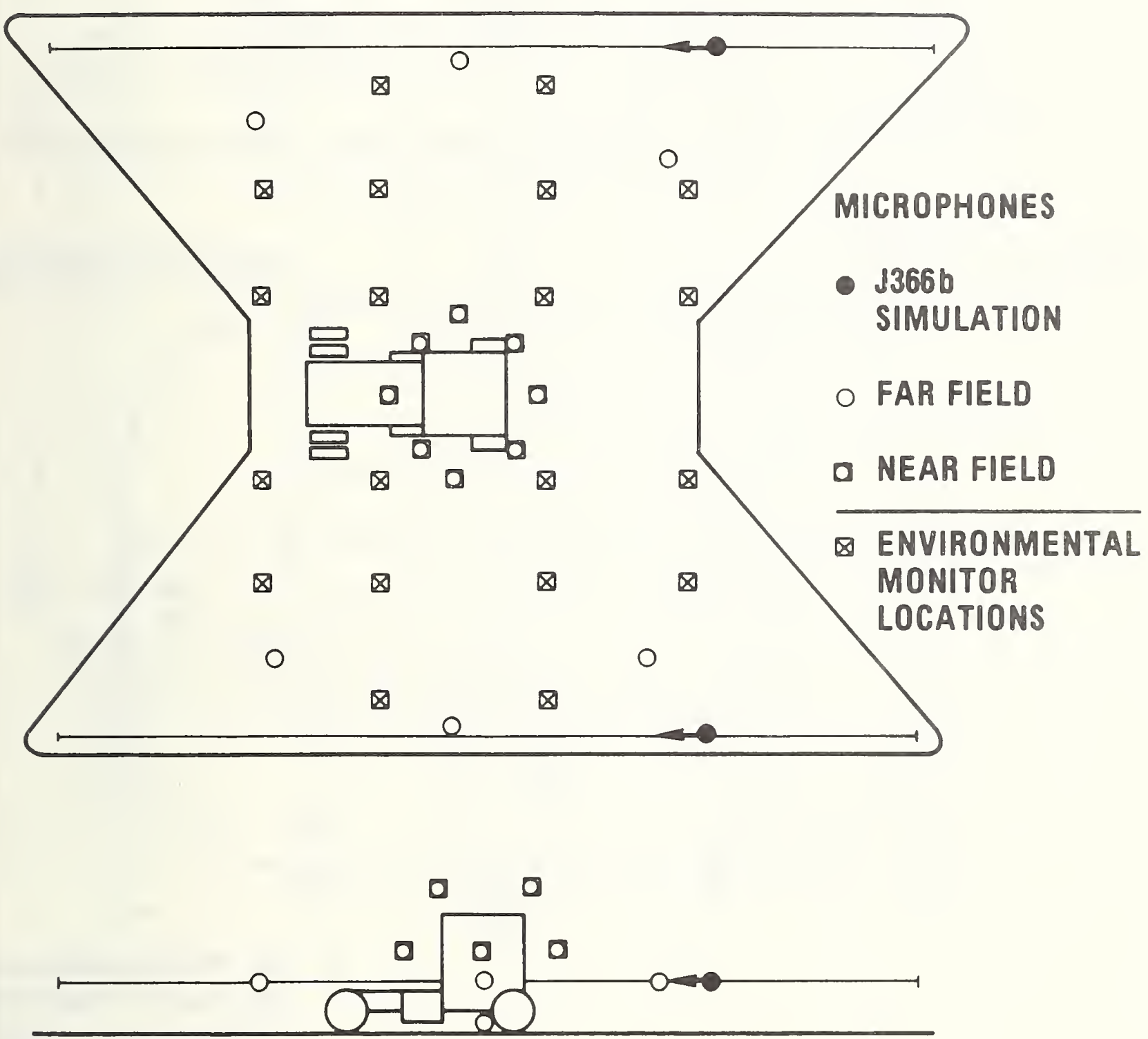

Figure 17. Schematic diagram for stationary vehicle test site showing transducer array locations. 

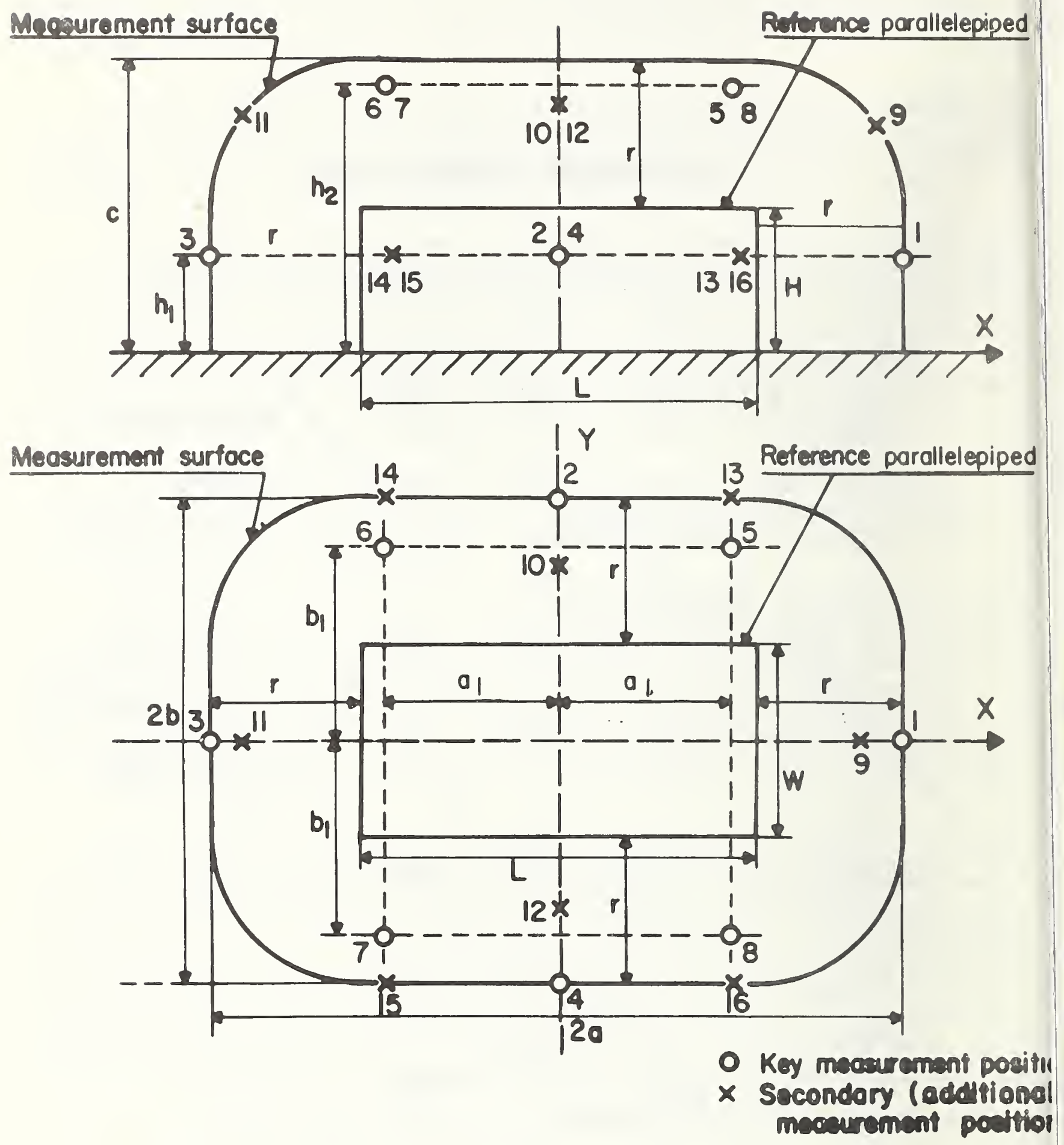

Figure 18. Location of measurenent positions on the measurement surface [21]. 
Table 3. Microphone position coordinates [21].

Source reference surface dimensions are L, W, H.

$$
\begin{aligned}
& a=\frac{L}{2}+r, b=\frac{W}{2}+r, c=H+r \\
& h_{1}=\frac{1}{2}\left(a+b-\frac{r}{2}\right), \text { if } h_{1} \text { is greater than } H \text { then take } h_{1}=H \\
& a_{1}=\frac{1}{2}\left(a+\frac{r}{2}\right), \text { if } a_{1} \text { is greater than } \frac{L}{2} \text { then take } a_{1}=L / 2 \\
& b_{1}=\frac{1}{2}\left(b+\frac{c}{2}\right), \text { if } b_{1} \text { is greater than } b \text { then take } b_{1}=b
\end{aligned}
$$

\begin{tabular}{|c|c|c|c|c|}
\hline Position Number & $\mathrm{X}$ & $\mathrm{Y}$ & $\mathrm{Z}$ & $\begin{array}{c}\text { Distance from } \\
\text { reference surface }\end{array}$ \\
\hline 2 & $\mathrm{a}$ & 0 & $\mathrm{~h}_{1}$ & $\mathrm{r}$ \\
3 & 0 & $\mathrm{~b}$ & $\mathrm{~h}_{1}$ & $\mathrm{r}$ \\
4 & $-\mathrm{a}$ & 0 & $\mathrm{~h}_{1}$ & $\mathrm{r}$ \\
5 & 0 & $-\mathrm{b}_{1}$ & $\mathrm{~h}_{1}$ & $\mathrm{r}$ \\
6 & $\mathrm{a}_{1}$ & $\mathrm{~b}_{1}$ & greater than $\mathrm{H}$ & $\mathrm{r}$ \\
7 & $-\mathrm{a}_{1}$ & $\mathrm{~b}_{1}$ & greater than $\mathrm{H}$ & $\mathrm{r}$ \\
8 & $-\mathrm{a}_{1}$ & $-\mathrm{b}_{1}$ & greater than $\mathrm{H}$ & $\mathrm{r}$ \\
\hline
\end{tabular}

Origin for the coordinate system is the point on the ground plane under the geometric center of the source. 


$$
\begin{aligned}
& \mathrm{a}_{1}=1 / 2(2.25+1 / 2)=1.375 \mathrm{~m},>\frac{2.5}{2} ; \quad a_{1}=1.25 \mathrm{~m} \\
& \mathrm{~b}_{1}=1 / 2(2.5+(3+1) / 2)=2.25 \mathrm{~m}
\end{aligned}
$$

These locations are shown schematically in Figure 19. Note that minor projections from the surface including bumpers, handles, fuel tanks, exhaust pipes and air intake are ignored in determining the reference surface unless there are known to be sources which penetrate the measurement surface.

It is expected that some experimental checks of measurement precision (i.e., sampling error) will be made during the first measurement trip by recording data at additional positions (see secondary measurement positions Figure 18). These data will be used to determine an estimate of probable sampling error using the eight point array.

In addition to the J366b microphone positions, additional far field fixed measurement positions are planned. Three data channels are available for this purpose and transducers will be positioned to obtain horizontal and vertical directivity information for comparison with driveby measurements. In addition, it is expected that these data will be used to obtain information for studies of the environmental effects on propagation without the added complication of a moving source-receiver geometry.

Vehicle operational parameter data will be recorded as for the moving vehicle tests, except that engine speed and horsepower data will be derived from existing test facility transducers.

Environmental variables and test site measurements will be recorded as for the moving vehicle measurements.

\section{b. Test Plan for Stationary Tests}

As discussed previously for the moving tests, the schedule for testing will be arranged in such a manner that the possibilities of systematic biasing of the data will be minimized. To assure this, the order in which the tests are performed will be randomized as much as feasible, considering the limitations of set up and calibration of instrumentation and changes of vehicle configurations. The controlled variables in the stationary test are:

1. Vehicles: I, II, III

2. Vehicle configurations: A - whole truck

B - without fan

C - without exhaust or fan and exhaust

D - fan only

3. Time of day: day, night 


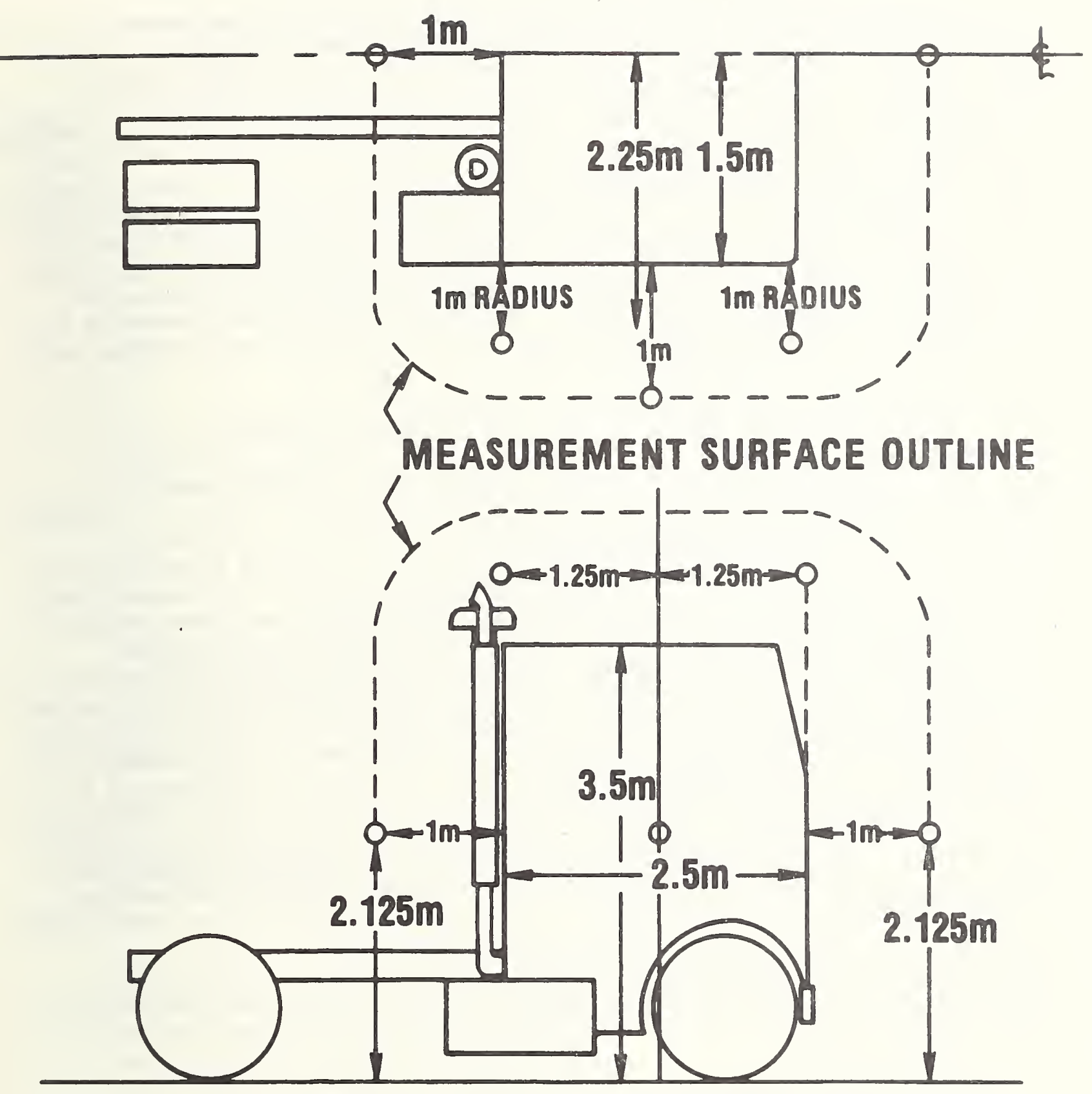

Figure 19. Plan and elevation of near field microphone array. 
As defined in the previous section, day is the time period when the temperature gradient is a maximum due to the heating of the test pad (e.g., 1:00 to 5:00 p.m.) and night as the time period when the temperature gradient is a minimum (late evening or early morning).

A typical test plan, which would be completed in three calendar days and repeated during each of the five (or six) field trips, is outlined in Table 4. Also given in this table is an estimate of the time required for each test. For each test condition there are expected to be 5 simulated J366b drivebys and 5 stationary run-ups. Using this test plan the order of testing the individual vehicles and vehicle configurations will each be randomized for a field trip. This test plan represents the approximate schedule that will be followed during the second week of the first trip and all subsequent trips. During the first week of the first trip approximately two days will be spent in familiarization with the stationary test site and its operation. One day will be spent in setting up equipment and making site evaluation measurements. The second day will be used to record simulated drivebys and stationary run-ups of one vehicle using all four configurations during both the day and night conditions, to evaluate test procedures.

\subsection{Variations from the Proposed Test Plan}

This experiment breaks new ground in several areas with respect to current technology on vehicle noise measurements, either in scale or in kind. Several of these areas have been identified in previous discussions, including, test site evaluation, comparability of stationary simulation vs. moving vehicle tests, on-board vehicle parameter and near field sound level monitoring, vehicle near field sound power measurements, and environmental variables monitoring. Because of inherent technological difficulties associated with these several areas, the proposed measurement program should be regarded as describing the intentions of a cautiously optimistic principal investigator, with the realization that some modifications may be necessary in view of state-of-the-art instrumentation limitations. In particular, the structureborne noise problems associated with mounting a microphone on a moving vehicle are recognized as presenting serious design problems which may not be solveable without a separate research program of substantial extent. Further, the scale of the experiment in terms of the number of simultaneous operating transducers and recorders is an invitation to interruption from "bugs" and "glitches". As a result, the proposed test plans are to be viewed as subject to minor modification to overcome these problems, at the discretion of the principal investigator. Major changes, arising from instrumentation limitations or new knowledge derived from this experiment or other investigators, will be made with the concurrence of the MVMA Vehicle Sound Level Committee.

In this latter regard, it is appropriate to discuss in somewhat greater detail, two possible major changes which might be anticipated, including change in the scope of the tests motivated by inspection of preliminary data, and changes due to evaluation of vehicle mounted microphone performance. 
Table 4. Test plan for stationary tests giving the order of vehicle testing.

\begin{tabular}{|c|c|c|c|}
\hline $\begin{array}{l}\text { Time } \\
\text { of Day }\end{array}$ & $\begin{array}{l}\text { Test } \\
\text { Vehicles }\end{array}$ & $\begin{array}{l}\text { Test Vehicle } \\
\text { Configuration }\end{array}$ & $\begin{array}{l}\text { Estimated Time for Set Up } \\
\text { or for } 5 \text { Simulated Drivebys } \\
\text { and } 5 \text { Stationary Run-Ups }\end{array}$ \\
\hline \multicolumn{3}{|c|}{ Instrumentation Set Up and Calibration } & 1 hour \\
\hline DAY & $\mathbf{I}$ & $\begin{array}{l}\text { A } \\
\text { B } \\
\text { C } \\
\text { D }\end{array}$ & $\left.\begin{array}{ll}20 & \text { minutes } \\
20 & \text { minutes } \\
20 & \text { minutes } \\
20 & \text { minutes }\end{array}\right\}$ \\
\hline \multicolumn{3}{|c|}{$\begin{array}{l}\text { Disassembly of Instrumentation to Protect } \\
\text { Against Damage During Time Allowed for } \\
\text { Environmental Variables to Change }\end{array}$} & Minimum \\
\hline \multicolumn{3}{|c|}{ Instrumentation Set Up and Calibration } & 1 hour \\
\hline $\begin{array}{l}\text { NIGHT } \\
\text { (1) }\end{array}$ & I & $\begin{array}{l}\text { B } \\
\text { C } \\
\text { D } \\
\text { A }\end{array}$ & $\left.\begin{array}{ll}20 & \text { minutes } \\
20 & \text { minutes } \\
20 & \text { minutes } \\
20 & \text { minutes }\end{array}\right\}$ \\
\hline \multicolumn{3}{|c|}{ Instrumentation Set Up and Calibration } & 1 hour \\
\hline DAY & II & $\begin{array}{l}\text { D } \\
\text { C } \\
\text { B } \\
\text { A }\end{array}$ & $\left.\begin{array}{l}20 \text { minutes } \\
20 \text { minutes } \\
20 \text { minutes } \\
20 \text { minutes }\end{array}\right\}$ \\
\hline \multicolumn{3}{|c|}{$\begin{array}{l}\text { Disassembly of Instrumentation to Protect } \\
\text { Against Damage During Time Allowed for } \\
\text { Environmental Variables to Change }\end{array}$} & Minimum $\quad 4$ hours \\
\hline \multicolumn{3}{|c|}{ Instrumentation Set Up and Calibration } & 1 hour \\
\hline $\begin{array}{l}\text { NIGHT } \\
\text { (2) }\end{array}$ & II & $\begin{array}{l}\text { C } \\
\text { B } \\
A \\
\text { D }\end{array}$ & $\left.\begin{array}{l}20 \text { minutes } \\
20 \text { minutes } \\
20 \text { minutes } \\
20 \text { minutes }\end{array}\right\}$ \\
\hline \multicolumn{3}{|c|}{ Instrumentation Set Up and Calibration } & 1 hour \\
\hline $\begin{array}{l}\text { DAY } \\
\text { (3) }\end{array}$ & II I & $\begin{array}{l}\text { B } \\
\text { A } \\
\text { C } \\
\text { D }\end{array}$ & $\left.\begin{array}{ll}20 & \text { minutes } \\
20 & \text { minutes } \\
20 & \text { minutes } \\
20 & \text { minutes }\end{array}\right\} 21 / 2$ hours \\
\hline \multicolumn{3}{|c|}{$\begin{array}{l}\text { Disassembly of Instrumentation to Protect } \\
\text { Against Damage During Time Allowed for } \\
\text { Environmental Variables to Change }\end{array}$} & Minimum $\quad 4$ hours \\
\hline \multicolumn{3}{|c|}{ Instrumentation Set Up and Calibration } & 1 hour \\
\hline $\begin{array}{l}\text { NI GHT } \\
\text { (3) }\end{array}$ & III & $\begin{array}{l}\text { C } \\
\text { D } \\
\text { B } \\
\text { A }\end{array}$ & $\left.\begin{array}{ll}20 & \text { minutes } \\
20 & \text { minutes } \\
20 & \text { minutes } \\
20 & \text { minutes }\end{array}\right\}$ \\
\hline
\end{tabular}


A decision point has been indicated in the experiment at the completion of data reduction from the third measurement trip. At this point, it is expected that it will be possible to project the sensitivity of the experiment to systematic variations for all of the variables under study, based on data to date and anticipated trips. Thus, depending on the outcome of an evaluation of these data, the total additional data needs can be reviewed and modified as indicated. In particular, the need for more or fewer measurement trips than the two subsequent planned trips can be discussed.

Unfortunately, the matrix of possible outcomes of the experiment at that point is so large, that speculation on their variety, and the implied actions which might be taken, is probably unjustified.

\section{b. Changes in Experiment because of Vehicle Mounted Near Field Microphones}

The principal purpose of the stationary tests is to permit the acquisition of near field sound power data during the equivalent of a J366b driveby test. The objective of this data is to permit deduction of the dependence of vehicle emission on environmental variables from direct observations rather than through more complex analysis procedures. If an alternative procedure for deriving these data can be found, without stationary tests, then these tests could be dispensed with. A vehicle mounted microphone array would permit this, if the data so derived were of adequate quality. Three, as yet incompletely understood, technological problems are of significance to the quality of this data. These include: a) the structureborne vibration question, already mentioned; b) the quality necessary as compared with the bandwidth and dynamic range of telemetry equipment; and c) the wind noise problem. Unfortunately, only testing experience can reveal whether or not these problems can be adequately solved. In the event that the problems can be solved to an acceptable degree, a proposal using this alternative can be expected. In this event the stationary run-up tests will be performed with the vehicle parked in the center of the measurement area of the driveby test site.

\section{DATA REDUCTION AND REPORTING}

This section outlines the proposed data reduction and reporting to be performed in conjunction with this study.

\subsection{Data Reduction}

Acoustic data reduction implies dealing with several different types of data, including J366b microphone data, horizontal directivity data, vertical directivity data, moving source near field microphone data, near field sound power data, stationary source far field data, all repeated for the number of multiple sources, source configurations and replications. As has already been noted this information will be reduced using a real time analyzer into $1 / 3$ octave band spectra, plus A-weight and linear sound level integrated over 
100 ms time periods. Since the vehicles are presumably traveling at speeds of $35 \mathrm{mph}(51.3 \mathrm{ft} / \mathrm{s}$ or $56.3 \mathrm{~km} / \mathrm{hr})$ or less and position information for moving tests is determined every 5 feet $(1.5 \mathrm{~m})$, the start of each $100 \mathrm{~ms}$ integration will be keyed on a position pulse and will thus represent the average sound level while the vehicle traverses a particular 5 foot $(1.5 \mathrm{~m})$ interval. Studies of initial data will be made to verify that this reduction procedure does not yield spurious data due to the arbitrary choice of the start of integration time and that the maximum values produced are compatible with the fast response circuit of a sound level meter. The stationary vehicle tests can similarly be handled, since relative position is systematically related to time through the (constant) microphone traverse speed. Additional study of the reduction procedure for these data will be required, however, in order to verify that simply sampling for $100 \mathrm{~ms}$ at the corresponding positions is an adequate representation. A first alternative involves using an appropriately time scaled integration time, consistent with the time scaling of the test (e.g., 1 second integration period for a nominal 10:1 time scale factor).

Data for a given microphone channel, reduced by the above procedure will be corrected for instrumentation level calibration, frequency response and background noise and will be stored as $\mathrm{n} x \mathrm{~m}$ dimensional matrices with $\mathrm{n}$ frequencies and $m$ source positions and an associated column matrix of time vs. position. These matrices will be interleaved sequentially with matrices of the appropriate vehicle parameter and environmental data. Since it is planned that the preliminary data analysis (except for horizontal plane directivity) will concentrate on maximum A-weighted sound level at the J366b microphone an additional separate data file will be written containing these data, except that horizontal plane directivity data will be rewritten for the vehicle position corresponding to the array center, rather than the position of maximum noise.

Vehicle parameter data will be reduced by first transcribing position code data onto the vehicle parameter tape, and then using the position code to identify sample intervals. Data will be sampled at a rate consistent with the rate of data change (typically 20 times per second) and corrected according to calibration tables, and also the reference temperature for thermocouple data. (Calibration data on driveshaft torque bridges will be derived from static tests made at NBS between field trips.) This data will be stored in $\mathrm{j} \times \mathrm{k}$ dimensional matrices with $\mathrm{j}$ parameters and $\mathrm{k}$ time intervals and position as an associated column.

Environmental parameter data will already be in digital format. Prior to transfer to storage, this data will be corrected according to calibration tables and then an average value and variance determined for the time period of about 1 minute duration surrounding each data run. These data will be stored in two (one for each tower) two-colum by $\mathrm{n}$ parameter matrices containing mean values and variances for each parameter. Data taken before or after each major test period, to identify spatial variation, will be reduced to means and variances versus position for evaluation as to spatial homogeneity. 
The purpose of the preliminary data presentation is to reveal progress of the experiment on three fronts, including: comparison of stationary simulation and moving tests, validity and utility of vehicle mounted near field microphone data, and evidence of systematic dependence of the acoustic data on environmental variables.

The comparison of stationary simulation and moving tests will proceed from two different areas of emphasis. The first might be called direct comparison through study of obvious acoustic data under comparable environmental conditions. The second, or indirect, method involves a comparison of the resulting "regression equations" for environmental dependence. For direct comparison we may compare the following in order of complexity:
a) Position(s) for maximum $A$-weighted level.
b) A-weighted sound level vs. position.
c) Spectra at positions of maximum A-weighted level.
d) Spectra vs. position for all positions.

Data for comparisons a) through c) will be routinely reported. Statistical analyses of these data for quantftative hypothesis testing are sufficiently complex that they must await later, more detailed, analyses.

Comparison of the "regression equations" will be permitted at a preliminary level since these equations and their confidence limits will be recomputed after each field trip.

Evaluation of the validity of vehicle mounted near field microphone data will be a major question during and after the first field trip. Field evaluation will emphasize identification of dynamic range and bandwidth of the actual signal, and the ability of the telemetry system to handle these, as well as estimates of structureborne noise and evaluation of the vibration isolation provided by the microphone supports. Later data analysis will provide information on comparability of spectra from vehicle mounted and ground mounted near field microphones during stationary tests, as well as wind and tire noise data from coastby measurements.

For preliminary analysis of environmental dependence, a total of eight sets of A-weighted maximum noise data are expected to be analyzed for each vehicle according to a statistical model similar to that described in Appendix A. The noise data to be analyzed are expected to include:

a) Moving vehicle test data: 
1. Whole truck.

2. Fan noise* (determined from whole truck less truck without fan).

3. Exhaust noise* (determined from truck without fan less truck without fan and exhaust).

4. Radiated noise* (i.e., truck without fan and exhaust).

b) Stationary test data:

1. Moving microphone, whole truck.

2. Moving microphone*, fan only.

3. Near field sound power*, whole truck.

4. Near field sound power*, fan only.

*Determined for the time interval or position producing maximum "whole truck" noise.

The environmental variables expected to be included in this analysis are mean temperature and the component of wind speed perpendicular to the vehicle axis at a selected elevation, relative humidity and ambient pressure. These results will be presented in the form of "regression" equations and selected graphs.

\subsection{Reports}

In order to convey the breadth of the findings in a timely manner, three meetings and seven written reports are planned (see overall test plan, section 3.1).

The meetings are planned to coincide with significant events in the experimental study as follows:

1. During the second week of field trip one, at the test site. Principal topic: test plan and near field data on moving vehicles.

2. After data reduction from field trip three, at NBS. Principal topic: test $\mathrm{plan}$ and data review.

3. After submission of draft final report, at MVMA headquarters. Principal topic: review of draft final report and proposal for detailed data analysis.

At the option of the Vehicle Sound Level Committee an additional meeting may be held at NBS at the conclusion of data analysis from the last trip, to 
review projected contents for the final report.

The written reports include trip reports at the conclusion of analysis of data from the previous trip, for the five planned trips (an additional report will be provided in the event that an optional trip is taken). The contents of a typical field report are expected to include:

1. Documentation of test plans and procedures if different from previous reports.

2. Ranges in environmental variables occuring during that trip and to date in the study.

3. Documentation of analytic and statistical analyses used in the preliminary data reduction, if different from previous reports.

4. Results of the preliminary statistical analyses including all data to date.

5. Projections of experiment sensitivity to detect changes due to variation in the environment according to projections of environment to be encountered.

6. Estimates of the magnitude of nonsystematic variations.

The two remaining reports are the final report and the proposal for detailed data analysis. The final report is expected to represent an integration of the several trip reports plus the results of the preliminary data re-analysis. (The data re-analysis is intended to confirm or modify the statistical model through a study of the data ensemble for missing variables (e.g., variables with significant correlation which were omitted from the primary statistical model) and correlation among the environmental variables. Either of these factors could lead to serious misinterpretations of the regression equations.

The proposal for data analysis will document in detail the types of problems to be studied and the scope of required effort for detailed analysis which is briefly discussed in the following section.

\section{DATA ANALYSIS}

Since an overall goal (restated) of this study is to provide information on the physical mechanisms by which the environment influences vehicle driveby noise measurements, it is appropriate to mention, at this point, some of the data analysis procedures which might reasonbly be used in such a study.

A rational model of the total physical process, subject to verification in this experiment is a differentiation into a time varying source of acoustic power ("the" vehicle) which injects a signal into a time varying 
multipath "transmission line" ("the" propagation path) which has a two pole terminal at each J366b microphone position. Both the "source" and the "transmission line" are subject to variation in their properties as a function of the environment. The near field data can be viewed alternatively, as is necessary, as a estimate of the envelope of power 1 nput to the "transmission line" or, when summed with phase and weighting information to predict directivity, as additional two pole terminals at

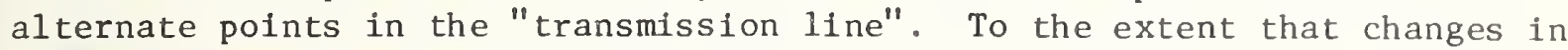
the environment can be characterized, and their influence on the source or path can be physically modeled, the effects can be regarded as systematic. Similarly, to the extent that the variables are not characterized or not modeled, the effects in terms of "explaining" the data are the same, i.e., non-systematic variation. As an example of the analysis program applied to these data, we pick one model component -- "the" path -- and one environmental variable -- wind -- leaving all other environmental factors constant, and pursue a thought experiment to see where this form of analysis might lead. If we look only at mean wind speed and its variance at some elevation and observe altered levels at the J366b microphones, study of the data might reveal little systematic and large non-systematic changes during repeated experiments. A physical model is introduced for changes in the propagation path which predicts that for a given change in effective sound speed and a particular source spectrum shape, the expected systematic changes due to a change in effective local sound speed are on the same order as the observed variations. Further, the magnitude of non-systematic changes is roughly correlated with the magnitude of wind speed variance. More refined analyses incorporating wind gradient are included in the model and re-analysis reveals that the new systematic variation is larger, and non-systematic variation is consequently reduced. Studies of the J366b microphone data over various source configurations might reveal that the dependence is different for fan sources than for exhaust or radiated noise, and that fan noise controls the whole vehicle data in many of the higher frequency bands. Further, the regression equations are found to be similar in each frequency band for which the fan is the controlling source. On the basis of this information, a physical model incorporating source variation dependent on relative wind speed into the fan is postulated and data are re-analyzed. More significant systematic variation is found, but significant non-systematic variation still exists. Analysis of near field vehicle mounted sound level data confirms the model at high frequencies for both whole vehicle and fan only data. Study of the horizontal plane directivity data indicates a modified directionality in the presence of transverse wind and an increase in relative level proportional to on axis wind speed at all points compared with no wind. Examination of the vertical directivity data confirms the predicted changes in the envelope of "transmission function" at several microphone heights, when gradient data are incorporated in the model as systematic variations in local sound speed with elevation. Finally the magnitude of the remaining non-systematic variation in sound level is found to be positively correlated with the average magnitude of wind speed fluctuations with time during the observation period.

We have described the process of confirming experimentally an analytic model of wind effect that has vehicle source dependence on magnitude and 
fluctuation of relative on axis wind speed, and path dependence on source spectrum, transverse wind speed, gradient and fluctuation with a residual unaccounted component. Thus, several sources of systematic variations have been identified for the purpose of this experiment. Whether all these variables are monitored in subsequent experiments or not is not significant since that will only determine whether or not they are classed as resulting in systematic or non-systematic variation for that observation condition. In either case, judicious estimates of their magnitude will provide, through the resultant "regression" equation, a basis for anticipating the magnitude of the effects.

The methodology for the analyses as outlined in the above thought experiment is expected to involve iteration processes in which a variation is noted and physical mechanisms hypothesized. Experiments which test the hypotheses are then "performed" by analysis of the data bank created from the experimental phase. The objective of the analyses is to reduce the observed non-systematic variation to a minimum by incorporating as much of the existing information in the data bank as is necessary to "explain" the observed variations. The tools to be used in the analyses will probably include examination of changes in apparent directivity and vehicle performance, use of narrowband frequency analysis for better source characterization, development of analytic models for path characterization and vehicle performance changes, as well as many of the multivariate statistical analysis procedures developed to date. A more detailed discussion of the data analyses to be pursued and emphasized will depend on the outcome of the preliminary data reduction which will provide an ordering of the apparent relative importance of the variables. 


\section{APPENDIX A}

\section{DESCRIPTION OF A DATA REDUCTION MATHEMATICAL MODEL}

It is difficult to describe the data reduction process in detail, without referring to a particular model. A simple model of this analysis will then be postulated for this discussion with no assurances that this is in fact the final model to be used for this purpose.

Figure A-1 shows a path diagram for the model. The $x_{i}$ in this diagram represent the measured variables, and the $e_{i}$ represent exogenous variables (e.g., error terms and other unmeasured or otherwise independent sources of variation), while the arrows represent apparent "connections" between the variables. When the variations of the variables are expressed in standardized form ( $1 . e .$, zero mean and unit variance) then the "connections" can be numerically evaluated as path coefficients ( $b_{j}$ ) which are found from the partial correlation coefficients $\left(r_{i j}\right)$ between the variables. Using this model the structural equation for variation in sound level is of the form,

$$
\mathrm{x}_{5}=\mathrm{b}_{15} \mathrm{x}_{1}+\mathrm{b}_{25} \mathrm{x}_{2}+\mathrm{b}_{35} \mathrm{x}_{3}+\mathrm{b}_{45} \mathrm{x}_{4}+\mathrm{b}_{55} \mathrm{e}_{5} \text {. }
$$

In this equation, since $i t$ is for standardized variables, the coefficient $b_{55}$ gives directly the fraction of the total variation in $x_{5}$ (sound level) which is not correlated with variation in the four variables which have been included. If this coefficient is too large relative to the other coefficients, it may potentially be reduced by the inclusion of other variables (implying an expansion of the model), or by the inclusion of additional data on the variables already included (1.e., more tests). The correlations between the other variables can be used to indicate to what extent they are independent of each other so that the significance of the final structural equation can be evaluated. Either (or preferably both) of two criteria can be used to determine when sufficient data have been collected. The first criterion already mentioned is the magnitude of the term $b_{55}$. The second criterion is the stability of the coefficients $b_{j 5}$ to the addition of new data, or equivalently, the cross-validation of the equations with a new data set.

The structural equation can be reformulated in physical units to resemble a regression equation through the relation of the physical variable to the standardized form, i.e.,

$$
y_{i}-\bar{y}=s_{i} x_{i}
$$

where $\bar{y}$ is the average value of the set of physical measurements $y_{i}$, and $s_{i}$ is the standard deviation of that set. Thus, the variation in sound level $1^{i}$ equation, presented earlier, would be given by,

$$
\text { VSL }=s_{5}\left[\frac{b_{51}}{s_{1}} y_{1}+\frac{b_{52}}{s_{2}} y_{2}+\frac{b_{53}}{s_{3}} y_{3}+\frac{b_{54}}{s_{4}} y_{4}+b_{55} e_{5}\right]+k \text {, }
$$




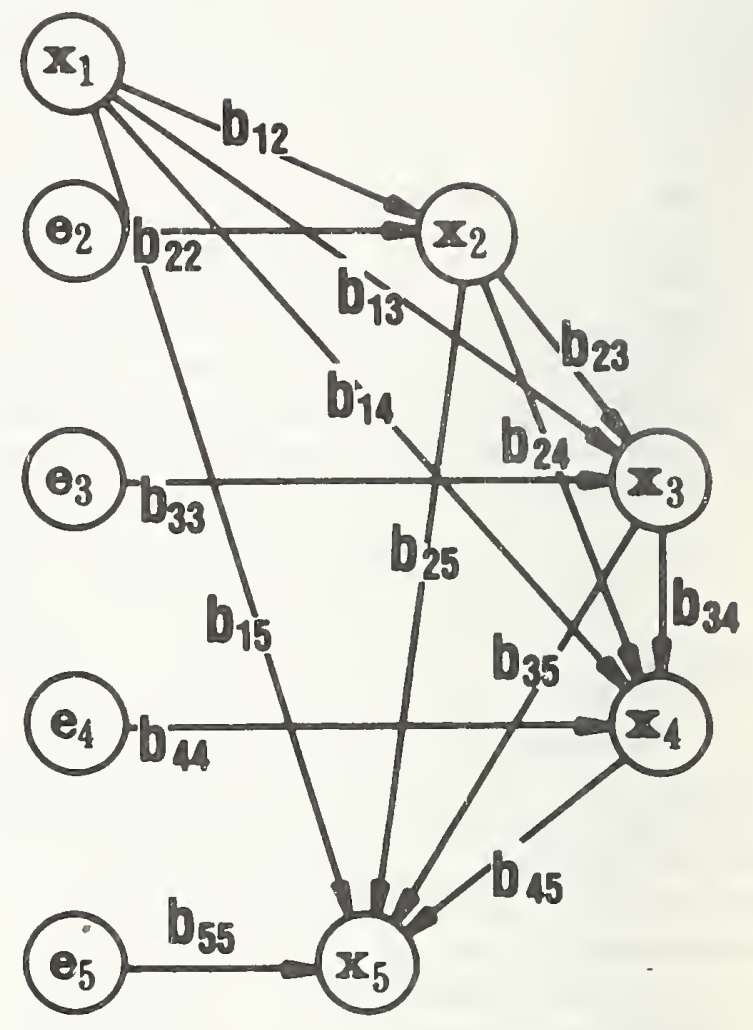

$$
\begin{aligned}
& x_{1}=\text { TEMPERATURE } \\
& x_{2}=\text { WIND } \\
& x_{3}=\text { PRESSURE } \\
& x_{1}=\text { RELATIVE HUMIDITY } \\
& x_{5}=\text { SAE SOUND LEVEL }
\end{aligned}
$$

Figure A-1. Hypothetical model for preliminary reduction of the data to illustrate process. 
where $s_{j}, b_{i j}$, and $e_{5}$ are defined in the previous equations, VSL is the variation in sound level $(\mathrm{dB}), K$ is an appropriate constant, and $y_{i}$ are the appropriate physical variables. In this example, y, would represent the temperature (degrees celsius for example) and the coefficient,

$$
\frac{s_{5} b_{51}}{s_{1}}=c_{1} \text {, }
$$

would have the dimensions of $\mathrm{dB} /{ }^{\circ} \mathrm{C}$. 


\section{REFERENCES}

[1] Society of Automotive Engineers, Inc., J366b - Exterior Sound Level for Heavy Trucks and Buses, SAE Recommended Practice (Society of Automotive Engineers, Inc., Warrendale, Pa., 1973).

[2] Leasure, Jr., W. A., and Quindry, T. L., Methodology and Supporting Documentation for the Measurement of Noise from Medium and Heavy Trucks, NBSIR 74-517 (National Bureau of Standards, Washington, D. C., June 1974).

[3] American National Standard Specification for Sound Level Meters, S1.4-1971 (American National Standards Institute, New York, N. Y., April 1971).

[4] Society of Automotive Engineers, Inc., J184 - Qualifying A Sound Data Acquisition System, SAE Recommended Practice (Society of Automotive Engineers, Inc., Warrendale, Pa., 1970).

[5] U. S. Environmental Protection Agency Final Noise Emission Standards, Motor Carriers Engaged in Interstate Commerce, Title 40, Code of Federal Regulations Chapter I, Part 202, U. S. Federal Register 39(209), 38208 38216 (October 29, 1974).

[6] U. S. Department of Transportation, Federal Highway Administration Final Regulation, Compliance with Interstate Motor Carrier Noise Emission Standards, Title 49, Code of Federal Regulations Chapter III, Part 325, U. S. Federal Register 40 (178), 42432 - 42441 (September 12, 1975).

[7] Baade, P.K., Sound Radiation of Air-Conditioning Equipment; Measurement in the Free Field Above a Reflecting Plane, ASHRAE Transactions 70, 217-227 (1964).

[8] Baade, P. K., Standardization of Machinery Sound Measurement, ASME Paper 69-WA/FE-30, presented at the ASME Winter Annual Meeting, Los Angeles, California (November 1969).

[9] Morse, P. M., and Ingard, U., Theoretical Acoustics (McGraw-Hill Book Company, Inc., New York, N. Y., 1968).

[10] Junger, M. C., and Feit, D., Sound, Structures, and Their Interactions (The MIT Press, Cambridge, Massachusetts, 1972).

[11] Ingard, U., and Maling, Jr., G. C., On the Effect of Atmospheric Turbulence on Sound Propagated over Ground, J. Acoust. Soc. Am. 35 (7), 1056-1058 (July 1963).

[12] 01son, N., Piercy, J. E., and Embleton, T. F. W., Variability in the Noise Testing of Light Motor Vehicles, presented at the 9lst meeting of the Acoustical Society of America, Washington, D. C. (Apri1 1976). 
[13] Society of Automotive Engineers, Inc., J986a - Sound Level for Passenger Cars and Light Trucks, SAE Recommended Practice (Society of Automotive Engineers, Inc., Warrendale, Pa., 1970).

[14] Holmer, C. I., Procedures for Estimating Sound Power from Measurements of Sound Pressure, Joint NBS-EPA Report EPA-550/8-76-001 (NBSIR 75-652)

(National Bureau of Standards, Washington, D. C., July 1975).

[15] Trott, W. J., Underwater-Sound-Transducer Calibration from Nearfield Data, J. Acoust. Soc. Am. 36, 1557-1568 (1964).

[16] Ferris, H. C., Computation of Farfield Radiation Patterns by Use of a General Integral Solution to the Time-Dependent Scalar Wave Equation, J. Acoust. Soc. Am. 41, 394-400 (1967).

[17] Kerns, D. M., Plane-Wave Spectra and Spectral Coupling Products for Arbitrary Radiating and Scattering Systems, NBS Report 10-719 (National Bureau of Standards, Boulder, Colorado, March 1972).

[18] Kerns, D. M., Plane-Wave Scattering Matrix and Generalized Reciprocity Relations for Antennas and Scatterers, NBS Report 10-720 (National Bureau of Standards, Boulder, Colorado, June 1972).

[19] Kerns, D. M., Scattering-Matrix Description and Near-Field Measurements of Electro-Acoustic Transducers, NBS Report 10-745 (National Bureau of Standards, Boulder, Colorado, July 1972).

[20] Van de Geer, J. P., Introduction to Multivariate Analys is for the Social Sciences (W. H. Freeman and Company, San Francisco, 1971).

[21] International Organization for Standardization Draft Proposal for Determination of Sound Power Levels of Noise Sources -- Engineering Methods for Free Field Conditions over a Reflecting Plane, ISO/DIS 3744 (American National Standards Institute, New York, N.Y.). 


\begin{tabular}{|c|c|c|c|}
\hline $\begin{array}{l}\text { U.S. DEPT. OF COMM. } \\
\text { BIBLIOGRAPHIC DATA } \\
\text { SHEET }\end{array}$ & $\begin{array}{l}\text { I. I'UIBI.IC ATION OR RI:PORT NO. } \\
\text { NBSIR } 76-1138\end{array}$ & $\begin{array}{l}\text { 2. Ciov't Acression } \\
\text { No. }\end{array}$ & 3. Recipient's Accession No. \\
\hline \multirow{2}{*}{\multicolumn{3}{|c|}{$\begin{array}{l}\text { 4. T Proposed Experiment to Evaluate Environmental Dependence } \\
\text { of the Measurement of Noise from Medium and Heavy Duty } \\
\text { Trucks }\end{array}$}} & $\begin{array}{l}\text { 5. Publication 1)atc } \\
\text { September } 1976\end{array}$ \\
\hline & & & 6. Performing Organization Codc \\
\hline \multicolumn{3}{|c|}{$\begin{array}{l}\text { 7. AuTHIOR(S) } \\
\text { Curtis I. Holmer and Roger D. Kilmer }\end{array}$} & $\begin{array}{l}\text { 8. Performing Organ. Report No. } \\
\text { NBSIR 76-1138 }\end{array}$ \\
\hline \multicolumn{3}{|c|}{$\begin{array}{l}\text { 9. PERFORMING ORGANIZATION NAME AND ADDRESS } \\
\text { NATIONAL BUREAU OF STANDARDS } \\
\text { DEPARTMENT OF COMMERCE } \\
\text { WASHINGTON, D.C. } 20234\end{array}$} & $\begin{array}{l}\text { 10. Project/Task/Work Unit No. } \\
2004571 \\
\text { 11. Coneract/Grane No. }\end{array}$ \\
\hline \multicolumn{3}{|c|}{$\begin{array}{l}\text { 12. Sponsoring Organization Name and Complete Address (Street, City, State, ZIP) } \\
\text { The Motor Vehicle Manufacturers Association } \\
\text { of the United States of America } \\
320 \text { New Center Building } \\
\text { Detroit, Michigan } 48202\end{array}$} & $\begin{array}{l}\text { 13. Type of Report \& Period } \\
\text { Covered } \\
\text { Final. Phase I } \\
\text { 14. Sponsoring Agency Code }\end{array}$ \\
\hline
\end{tabular}

15. SUPPLEMENTARY NOTES

16. ABSTRACT (A 200-word or less factual summary of most significant information. If document includes a significant bitliography or literature survey, mention it here.) Increasing concern with the impact of transportatio hoise on communities has led to an increase in the number of motor vehicle noise fegulations at all levels of government. As regulations become more widespread, the accuracy and precision of vehicle noise measurements become more critical since each incertainty in the measurement requires a corresponding increase in the margin that manufacturers must allow between the regulated noise 1 imit and vehicle design levels. Athough considerable uniformity has been achieved by existing voluntary standards, there femain significant variations between noise measurements made at different sites or at lifferent times on the same site. These variations are attributable to differences in th: environment, including site and meterological influences. Thus, there is a need for pystematic investigation of the various environmental and test site effects on noise generation, radiation and/or propagation. This report presents the findings of a feasibility study for an experiment to investigate environmental effects on truck noise emission measurements. The result of this study is a proposed experiment designed to examine the systematic and nonsystematic dependence of observed truck driveby noise on the environmental effects present during the measurement. The experiment is designed in such + manner as to permit separation of emission and propagation effects. Although it may nof qe feasible to determine "correction factors" for environmental effects within the time and financial constraints of this experiment, it is fully expected that the data obtained from this experiment will reveal the magnitude of variations in the measurement and provide a broad enough information base for study of the underlying physical mechanisms.

17. KEY WORDS (six to twelve entries; alphabetical order; capitalize only the first letter of the first key word unless a proper name; separated by semicolons)

Acoustics; environmental conditions; noise measurement; noise (sound); transportation noise; truck.

18. AVAII.ABHIITY IX InImited

For Offecial Dasirabuton. Do Nor Release a NTH

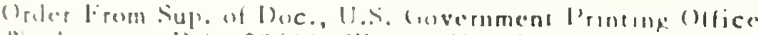

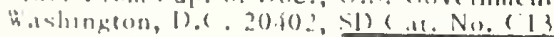

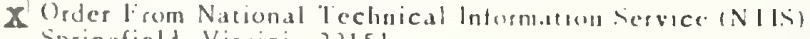
springficld, Virginial $2: 151$

\begin{tabular}{|c|c|}
\hline $\begin{array}{l}\text { 19. SECURITY CI.ASS } \\
\text { (THIS REPURT) } \\
\text { (INCI. ASSII:IEI) }\end{array}$ & $\begin{array}{l}\text { 21. NO. OF PAGES } \\
67\end{array}$ \\
\hline $\begin{array}{l}\text { 20. SIR (URITY ( I.ASS } \\
\left(1111 . S I^{\prime} A(, 1:)\right. \\
\text { INC I.ASSIIIII) }\end{array}$ & $\begin{array}{l}\text { 22. Price } \\
\$ 4.50\end{array}$ \\
\hline
\end{tabular}


NOTE: This report in July 1976 by S.G. Fattal was provided to OSHA and assigned NBS IR 76-1139; it was a restricted document for many years.

In 1998 Gail Hixenbaugh--while assisting another requestor seeking this document--received a copy of this document from OSHA and gave it to Karma Beal/NIST Archivist who shelved it with the Archive's IR's Harry Brooks 15Jun2K

2. In consideration of the findings by the National Bureau of

Standards research study, Report Number NBSIR 76-1139,

Investigation of Guardrails for the Protection of Employees from

Occupational Hazards, dated July 1976, this instruction permits the application of some applicable determinations in advance of the eventual promulgation of a revision to Subpart D of 29 CFR 1910.

Source:

OSHA Instruction STD 1-1.10

June 30,1981

Office of Compliance Programming

p. 2

at

http://www.osha-slc.gov/OshDoc/Directive_data/STD_1-1_10.html 
